\title{
First airborne water vapor lidar measurements in the tropical upper troposphere and mid-latitudes lower stratosphere: accuracy evaluation and intercomparisons with other instruments
}

\author{
C. Kiemle ${ }^{1}$, M. Wirth ${ }^{1}$, A. Fix ${ }^{1}$, G. Ehret ${ }^{1}$, U. Schumann ${ }^{1}$, T. Gardiner ${ }^{2}$, C. Schiller ${ }^{3}$, N. Sitnikov ${ }^{4}$, and G. Stiller ${ }^{5}$ \\ ${ }^{1}$ Deutsches Zentrum für Luft- und Raumfahrt, Inst. für Physik der Atmosphäre, Oberpfaffenhofen, 82234 Wessling, Germany \\ ${ }^{2}$ National Physical Laboratory, Teddington, UK \\ ${ }^{3}$ Forschungszentrum Jülich GmbH, Jülich, Germany \\ ${ }^{4}$ Central Aerological Observatory, Dolgoprudny/Moscow, Russia \\ ${ }^{5}$ Institut für Meteorologie und Klimaforschung, Karlsruhe, Germany
}

Received: 12 March 2008 - Published in Atmos. Chem. Phys. Discuss.: 2 June 2008

Revised: 4 August 2008 - Accepted: 7 August 2008 - Published: 4 September 2008

\begin{abstract}
In the tropics, deep convection is the major source of uncertainty in water vapor transport to the upper troposphere and into the stratosphere. Although accurate measurements in this region would be of first order importance to better understand the processes that govern stratospheric water vapor concentrations and trends in the context of a changing climate, they are sparse because of instrumental shortcomings and observational challenges. Therefore, the Falcon research aircraft of the Deutsches Zentrum für Luftund Raumfahrt (DLR) flew a zenith-viewing water vapor differential absorption lidar (DIAL) during the Tropical Convection, Cirrus and Nitrogen Oxides Experiment (TROCCINOX) in 2004 and 2005 in Brazil. The measurements were performed alternatively on three water vapor absorption lines of different strength around $940 \mathrm{~nm}$. These are the first aircraft DIAL measurements in the tropical upper troposphere and in the mid-latitudes lower stratosphere. Sensitivity analyses reveal an accuracy of $5 \%$ between altitudes of 8 and $16 \mathrm{~km}$. This is confirmed by intercomparisons with the Fast In-situ Stratospheric Hygrometer (FISH) and the Fluorescent Advanced Stratospheric Hygrometer (FLASH) onboard the Russian M-55 Geophysica research aircraft during five coordinated flights. The average relative differences between FISH and DIAL amount to $-3 \% \pm 8 \%$ and between FLASH and DIAL to $-8 \% \pm 14 \%$, negative meaning DIAL is more humid. The average distance between the probed air masses was $129 \mathrm{~km}$. The DIAL is found to have no
\end{abstract}

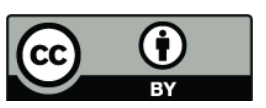

Correspondence to: C. Kiemle (christoph.kiemle@dlr.de) altitude- or latitude-dependent bias. A comparison with the balloon ascent of a laser absorption spectrometer gives an average difference of $0 \% \pm 19 \%$ at a distance of $75 \mathrm{~km}$. Six tropical DIAL under-flights of the Michelson Interferometer for Passive Atmospheric Sounding (MIPAS) on board ENVISAT reveal a mean difference of $-8 \% \pm 49 \%$ at an average distance of $315 \mathrm{~km}$. While the comparison with MIPAS is somewhat less significant due to poorer comparison conditions, the agreement with the in-situ hygrometers provides evidence of the excellent quality of FISH, FLASH and DIAL. Most DIAL profiles exhibit a smooth exponential decrease of water vapor mixing ratio in the tropical upper troposphere to lower stratosphere transition. The hygropause with a minimum mixing ratio of $2.5 \mu \mathrm{mol} / \mathrm{mol}$ is found between 15 and $17 \mathrm{~km}$. A high-resolution ( $2 \mathrm{~km}$ horizontal, $0.2 \mathrm{~km}$ vertical) DIAL cross section through the anvil outflow of tropical convection shows that the ambient humidity is increased by a factor of three across $100 \mathrm{~km}$.

\section{Introduction}

Water vapor is a key atmospheric trace gas with important implications for both weather and climate: in the lower troposphere water vapor has the largest impact on precipitation (Keil et al., 2008); in the middle and upper troposphere it accounts for a large part of the atmospheric greenhouse effect and is believed to be an important amplifier of climate change (Held and Soden, 2000); stratospheric water vapor plays an important role in the radiation budget of the troposphere. Changes in upper-tropospheric water vapor in response to a

Published by Copernicus Publications on behalf of the European Geosciences Union. 
warming climate are the subject of significant debate (Trenberth et al., 2007). For example, indirect effects through changing cirrus or convective clouds could impact the radiation balance of the upper troposphere (UT) and lower stratosphere (LS). In the stratosphere the level of scientific understanding of water vapor trends and of radiative forcing by water vapor is very low (Forster et al., 2007). Global climatechemistry model simulations show a linear relationship between ozone reduction and stratospheric water vapor increase via the augmentation of the presence of $\mathrm{OH}$ radicals and polar stratospheric clouds (Stenke and Grewe, 2005). The two principal sources for water in the stratosphere are methane oxidation and transport from the troposphere. The latter is difficult to quantify because the particular thermodynamical conditions in the UT/LS (low temperature, pressure and water vapor; high solar irradiance) lead to chemical and nucleation processes different from those known elsewhere in the atmosphere. Laboratory data of surface nucleation and field data on particle properties are presently too limited to allow any conclusions to be drawn (Peter et al., 2006).

In the tropics the "tropical tropopause layer" (TTL) couples the Hadley circulation of the mainly convectively driven tropical troposphere with the much slower Brewer-Dobson circulation of the predominantly radiatively controlled stratosphere. It is commonly defined as the layer extending from the level of main convective outflow to the cold point tropopause. Laterally the TTL is bounded by the subtropical jet streams which vary seasonally both in their intensity and meridional position. Radiative transfer models show that in a cloud-free TTL, water vapor is the most important contributor to the radiation balance. Together with carbon dioxide and ozone, net radiative heating dominates above 15 $( \pm 0.5) \mathrm{km}$ whereas radiative cooling dominates below this level of balanced radiation budget (Gettelman et al., 2004). In clear sky an air parcel is therefore forced to ascend (descend) above (below) this level that is considered a borderline for UT-LS exchange. However, the presence of clouds significantly modifies the balance. Corti et al. (2005) fed their radiative transfer calculations with climatological and lidar cloud cover records and concluded that there is ,,considerable uncertainty concerning the influence of clouds on the radiative energy budget due to limited information on cloud vertical structure and optical depth“. This is particularly true for cirrus and subvisible cirrus. Spaceborne lidar observations could help reduce this uncertainty.

Although recent trajectory analyses consolidate the common understanding that tropospheric air primarily enters the stratosphere in the tropics (Fueglistaler et al., 2004), important details of this transport process remain uncertain. Various processes are supposed to be responsible for troposphereto-stratosphere transport hydrating the stratosphere: (1) large scale slow ascent in the TTL with subsequent quasiisentropic transport towards the poles (the Brewer-Dobson circulation). (2) Deep convection overshooting the level of neutral buoyancy, especially found over land, over central
Africa, Indonesia and South America (Liu and Zipser, 2005). For example, Chaboureau et al. (2007) describe the observation and simulation of an extreme event with very high vertical windspeed that occurred during TROCCINOX in Brazil. (3) Turbulent diffusion at the subtropical jet stream borders of the TTL and in the outflow regions of large-scale convective systems where horizontal and vertical gradients of wind and water vapor exist (Konopka et al., 2007). The contribution of each of these processes to the total transport is uncertain. It is furthermore not clear whether other processes such as deep convection or jet streams at mid-latitudes do contribute, too. Dehydration by freeze-drying at the tropical cold point tropopause limits the humidity in the LS and generates geometrically and optically thin cirrus. Little is known about the global cover, the nucleation processes and the characteristics of its particles (Luo et al., 2003; Peter et al., 2003, 2006; Kärcher, 2004).

One reason for the lack in understanding is the fact that water vapor measurements are sparse because of instrumental and observational shortcomings. Instrumental shortcomings arise from the challenging thermodynamical conditions in the UT/LS. It is well known that the current radiosonde observational network fails to deliver accurate water vapor profiles in the UT/LS. But also sophisticated instrumentation on research aircraft or balloons is subject to malfunction and requires permanent calibration and validation efforts. Observational shortcomings aggravate the situation. For example, Kley et al. (1997) point out that observations can easily suffer a dry bias simply because most of the useful data stem from convection-free regions. Within deep convection, aircraft measurements are rare, balloons are destroyed or expelled from the core, and satellites cannot see through the anvils. Spaceborne passive remote sensors can potentially overcome the spatial and temporal limitations of ground or air-based instruments and provide long-term, global data down to the mid-troposphere. However, their skill to measure humidity in the tropics is severely reduced by the abundance of cirrus clouds and the coarse resolution in view of the fact that UT water vapor is highly variable in space and time. This also complicates instrument and model intercomparisons.

It was consequently time to carry out an experiment with a focus on water vapor in this particular region. The Tropical Convection, Cirrus and Nitrogen Oxides Experiment (TROCCINOX; http://www.pa.op.dlr.de/troccinox) in 2004 and 2005 in Brazil had two general objectives: (1) improve the knowledge on lightning produced nitrogen oxides in tropical thunderstorms by quantification of the produced amounts, by comparison to other major sources and by assessment of their global impact (Schumann and Huntrieser, 2007); (2) improve the knowledge on the occurrence of other trace gases including water vapor and particles (ice crystals and aerosols) in the UT/LS in connection with tropical deep convection as well as large scale upwelling motions. More specifically, TROCCINOX attempted to answer the following five questions: (1) what is the impact of tropical deep 
convection on the balance and distribution of nitrogen oxides and other trace gases? (2) How do troposphere-stratosphere exchange processes contribute to the amount of water vapor entering the stratosphere? (3) What is the effect of tropical deep convection on the formation and distribution of aerosol particles? (4) What are the origins of cirrus clouds in the tropics and how do they affect air composition? (5) How do tracer correlations across the sub-tropical barrier look like quantitatively and what does that mean for transport between the tropical and mid-latitudinal stratosphere? TROCCINOX involved the use of microphysical, radiation transfer, chemistry, transport and climate models, as well as aircraft, balloon and space observations. It was coordinated with the EU project HIBISCUS which gathered additional observations from balloons (Pommereau et al., 2007). The present paper is related to the general objective (2) and the specific question (2).

Airborne lidar is an excellent tool to probe the UT/LS. The mobile platform can quickly reach regions of particular interest like the outflow of convective systems. Another main advantage, especially over ground-based systems is the vertical vicinity to the regions of interest which provides a considerable advance in terms of accuracy and spatial resolution. On global average, $99.8 \%$ (in the tropics $99.9 \%$ ) of the total water vapor column is below $10 \mathrm{~km}$ altitude, so that groundbased remote sensing systems are nearly "blind" with respect to the UT/LS. The two-dimensional atmospheric cross sections of aerosol backscatter and water vapor complement and significantly go beyond conventional one-dimensional in-situ observations on balloons or aircraft. The DLR Falcon aircraft has windows in the fuselage bottom and top and is therefore an ideal platform for nadir and zenith profiling. With the lidar in zenith direction it was particularly successful in guiding the Geophysica into regions of interest such as subvisible cirrus at the tropical tropopause during a series of EUsponsored campaigns dedicated to UT/LS research. Airborne lidar with high accuracy and spatial resolution can shed light on UT/LS dynamics by using water vapor mixing ratio or background aerosol as air mass tracers (Ehret et al., 1999; Flentje and Kiemle, 2003). In 1999 the DLR lidar detected horizontally extended, persistent, optically and geometrically very thin cirrus layers at the tropical tropopause in the Indian Ocean (Thomas et al., 2002; Peter et al., 2003; Luo et al., 2003). Presently no instrument other than airborne lidar is capable to detect comparably low optical depths on the order of $10^{-3}$ to $10^{-4}$ because of the aforementioned advantages in combination with the use of very low-noise self-designed detectors.

Since water vapor DIAL measurements in the UT/LS are novel, quality control is mandatory. Comparisons with other instruments are the only method for the validation and calibration of remote sensors that cannot be checked in a laboratory. In the lower troposphere the DLR DIAL was successfully validated in the frame of a recent intercomparison study: the results were found to lie within $5 \%$ of the average of all instruments (Behrendt et al., 2007). In another study tropospheric DIAL profiles obtained during the TROCCINOX transfer flights between Europe and Brazil were compared with ECMWF analyses. An evaluation of the model's skill to reproduce tropical and subtropical water vapor fields gave an average moist bias of 0,6 and $11 \%$ for the model, relative to DIAL data from three transfer flights where the lidar was mounted nadir-viewing (Flentje et al., 2007). Finally, a recent study compared DLR DIAL profiles in the UT/LS from transfer flights between Europe and Australia to the SCOUT-O3 campaign (Stratospheric-Climate links with emphasis on the Upper Troposphere and Lower Stratosphere) with airborne microwave radiometer observations of stratospheric water vapor (Müller et al., 2008). They report very good agreement from the mid-latitudes to the tropics in the thin overlap region between 13 and $16 \mathrm{~km}$ altitude. The authors also find good agreement $(3.3 \% \pm 15 \%$ difference) with the Geophysica hygrometers FISH and FLASH that flew in parallel. More comprehensive UT/LS quality checks are lacking for DIAL, however. This is the motivation for the present study whose main purpose is to demonstrate the performance of airborne water vapor DIAL using carefully selected intercomparisons with other instruments.

In the next section we describe the water vapor DIAL, assess the instrument's accuracy, give an interesting measurement example and explain the comparison method. It is followed by Sect. 3 that details the results of comparisons of DIAL profiles with a balloon instrument, the Geophysica hygrometers and the MIPAS remote sensor onboard ENVISAT. The study is rounded off with a discussion of the DIAL profiles.

\section{The airborne DLR water vapor DIAL}

\subsection{System characteristics}

Differential absorption lidar is an appropriate technique for the remote sensing of atmospheric trace gases such as water vapor. A DIAL emits short light pulses into the atmosphere at two distinct wavelengths. The online wavelength is tuned to the center of a molecular water vapor absorption line. For the UT/LS region suitably strong and temperatureinsensitive absorption lines are found in the near-infrared around $940 \mathrm{~nm}$. The offline wavelength is the reference and contains information on the aerosol load and cloud cover of the probed atmosphere. The combination of both on- and offline return signals gives a profile of the water vapor molecule number density as function of the distance from the lidar. The DLR DIAL system transmitter is based on an injectionseeded optical parametric oscillator (OPO) pumped by the second harmonic of a Q-switched, diode-pumped singlemode running Nd:YAG laser with a repetition rate of $100 \mathrm{~Hz}$. Injection seeding by a single-mode running external cavity diode laser ensures that the online spectral bandwidth is an 
Table 1. DLR water vapor differential absorption lidar (DIAL) system characteristics.

\begin{tabular}{ll}
\hline DIAL System Parameters & \\
\hline Transmitter type & OPO $^{\mathrm{a}}$ \\
Pulse energy (mJ) & 12 \\
Pulse repetition rate $(\mathrm{Hz})$ & 100 \\
Bandwidth on-/offline $(\mathrm{GHz})$ & $0.14 / 90^{\mathrm{b}}$ \\
Spectral purity & $>99 \%^{\mathrm{b}}$ \\
Strong absorption line $(\mathrm{nm})$ & 935.6846 \\
Medium absorption line $(\mathrm{nm})$ & 935.6083 \\
Weak absorption line $(\mathrm{nm})$ & 935.5612 \\
Telescope diameter $(\mathrm{cm})$ & 35 \\
Detector type & $\mathrm{APD}^{\mathrm{c}}$ \\
Data sampling rate $(\mathrm{MHz})$ & 10 \\
A-D converter depth $(\mathrm{bit})$ & 14 \\
Horizontal resolution $(\mathrm{m})^{\mathrm{d}}$ & 5 \\
${\text { Vertical resolution }(\mathrm{m})^{\mathrm{d}}}^{\mathrm{d}}$ & 15 \\
Relative accuracy $(\%)^{\mathrm{e}}$ & 5.1 \\
\hline
\end{tabular}

a Optical parametric oscillator.

b Poberaj et al. (2002).

c Avalanche photo diode.

$\mathrm{d}$ Resolution of the unprocessed raw data.

e Total from Table 2 for measurements between 8 and $16 \mathrm{~km}$ altitude.

Table 2. DIAL accuracy in the UT/LS. Data from Fig. 1 averaged between 8 and $16 \mathrm{~km}$ altitude.

\begin{tabular}{llll}
\hline Parameter & Reference & Variation & Accuracy \\
\hline Rayleigh-Doppler effect & $\mathrm{BSR}=1.5^{\mathrm{a}}$ & $\mathrm{BSR}=1.0^{\mathrm{b}}$ & $3.7 \%$ \\
Laser spectral purity & $100 \%$ & $99 \%$ & $1.2 \%$ \\
Atm. pressure variation & balloon & $4 \mathrm{hPa}^{\mathrm{c}}$ & $1.4 \%$ \\
Atm. temper. variation & profile & $2 \mathrm{~K}^{\mathrm{c}}$ & $0.2 \%$ \\
Instrument noise & & & $3 \%$ \\
Total accuracy (RMS) & & & $5.1 \%$ \\
\hline
\end{tabular}

a Ratio of total (aerosol plus molecular) to molecular backscatter coefficients.

b No aerosol.

c Constant offset with altitude assumed.

order of magnitude narrower than the width $(\sim 1.5 \mathrm{GHz})$ of the water vapor absorption line in the UT/LS. The laser is stabilized by a computer controlled feedback loop based on a transmission measurement of the seed laser beam that is coupled into a multi-pass absorption cell filled with water vapor. The cell also controls the wavelength calibration on a pulse-by-pulse basis and the quantity of laser energy lying within the spectral bandwidth, the laser's spectral purity, that amounts to $99.4 \%$ on in-flight average (Poberaj et al., 2002).

The OPO has an average output power of $1.2 \mathrm{~W}$ and is tunable in the spectral region between $920-950 \mathrm{~nm}$. This allows

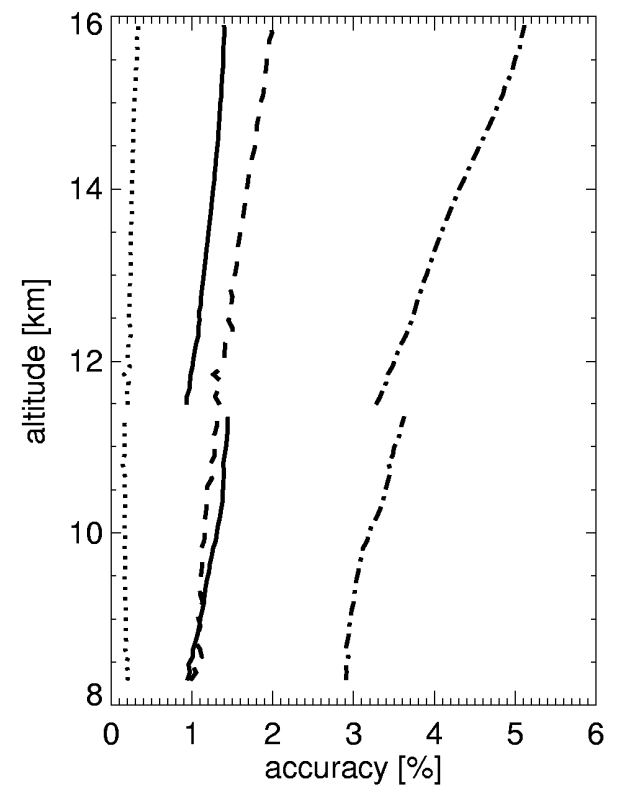

Fig. 1. DIAL accuracy for two profiles of Fig. 3 obtained with the strong (above $11.5 \mathrm{~km}$ ) and medium (below) absorption lines of Table 1. Sensitivities with respect to laser spectral impurity (solid), Rayleigh Doppler effect (dash-dotted), pressure (dashed) and temperature (dotted) are plotted versus altitude. The reference parameters and their variations are listed in Table 2.

taking advantage of absorption lines of different strength as a function of water vapor concentration and flight altitude, in order to adapt to the highly varying concentrations in the UT and to optimize the vertical range of the measurements. The in-flight switch from one absorption line to the other took only about 1 min including the time needed to find the new line and to stabilize the laser. This considerable tunable system advantage was used for the first time during TROCCINOX. Table 1 lists the three absorption lines used in this study, as well as the main system parameters. APD detectors with self-designed, low-noise and high-linearity amplifiers for the $940 \mathrm{~nm}$ signals are one of the key components that guarantee the system's excellent performance. Additional detectors at $532 \mathrm{~nm}$ and $1064 \mathrm{~nm}$ do polarizationsensitive backscatter measurements for aerosol and cloud particle characterization. On-board quicklooks display twodimensional aerosol backscatter cross sections in real-time. This is essential both for direct quality check and for the detection of interesting atmospheric regions to redirect the flight route or to guide another aircraft. All data are stored on tape and disks together with important system and aircraft parameters. A significant portion of the data evaluation process is devoted to quality control: profiles with too high noise level or with laser spectral purity lower than $98 \%$ are discarded before averaging.

The effective absorption cross section in the DIAL equation is computed with a spectrally highly resolved radiation 


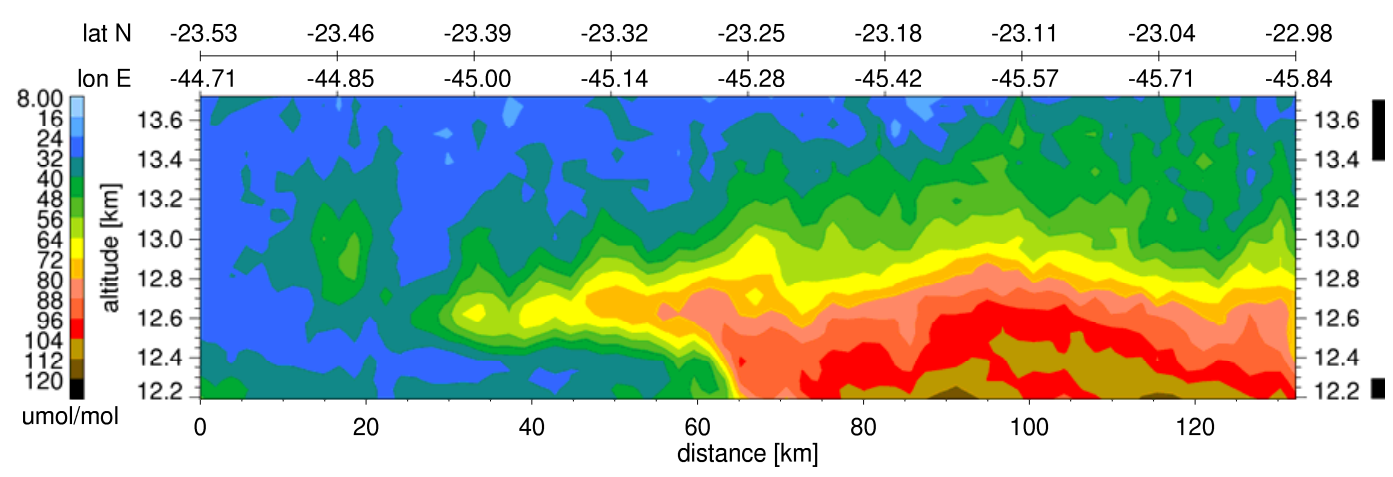

Fig. 2. Vertical cut of DIAL water vapor volume mixing ratio through the anvil outflow of a deep convective system into the clear-sky TTL on 3 March 2004 at 13:06 UTC. The horizontal resolution is $2 \mathrm{~km}$, the vertical $100 \mathrm{~m}$ (300 m) at the bottom (top); black boxes (right) symbolize the spatial resolution. The thunderstorm was located far outside the figure at $\sim 230 \mathrm{~km}$, with the anvil cirrus edge at $\sim 160 \mathrm{~km}$.

transfer code (Ehret et al., 1999), with the line parameters from the HITRAN 2004 database (Rothman et al., 2005), and with pressure and temperature profiles of the appropriate (tropical or mid-latitudes) standard atmosphere. The use of a standard profile is uncritical because the pressure and temperature sensitivity of the selected absorption lines is low, as will be shown in the following subsection. The main reason for using standard atmospheres was the lack of reliable profiles in the vicinity of the DIAL measurements. The standard atmosphere also provides the air density to convert the water vapor molecule number density measured by DIAL into volume mixing ratio, the common unit in the UT/LS. The typical pressure and temperature variations encountered in this study, addressed in the next section, lead to air density and hence conversion fluctuations of $\sim 2 \%$. This number includes the pressure and temperature dependencies of the selected absorption lines. The DIAL radiation transfer code has a number of additional indispensable tasks: (1) it accounts for the spectral Doppler broadening of the return signals by molecular scattering known as the Rayleigh Doppler effect (Ansmann and Bösenberg, 1987). (2) The laser stabilizing feedback loop works with the online wavelength slightly shifted off the absorption line center by $\sim 250 \mathrm{MHz}$ or $0.0083 \mathrm{~cm}^{-1}$ (Poberaj et al., 2002). The code corrects this shift that would result in a considerable dry bias of $4 \%(12 \%)$ at $8(16) \mathrm{km}$ altitude if not corrected. (3) For the offline measurements the laser is run in an unseeded mode at a spectral bandwidth (FWHM) of $90 \mathrm{GHz}$ or $3 \mathrm{~cm}^{-1}$. The code includes the absorption by water vapor lines within this span. (4) The code can correct the laser spectral impurity if the spectral line shape of the online pulse is known. As shown in the next section this effect is small in the UT/LS.

\subsection{Accuracy evaluation}

Table 2 gives an overview of the DIAL accuracy in the present study. The HITRAN 2004 database (Rothman et al., 2005) assigns to all three water vapor absorption lines of Ta-
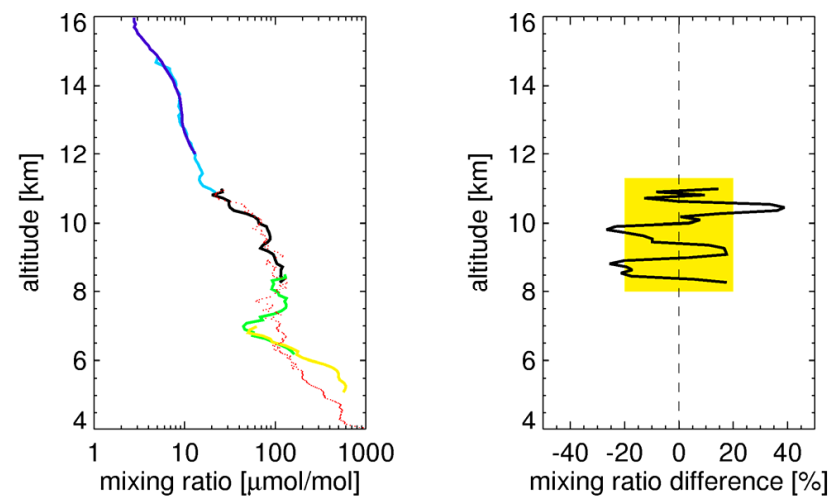

Fig. 3. Comparison between DIAL profiles (solid) and the TDLAS (tunable diode laser; red dotted) hygrometer onboard the HIBISCUS SF1 balloon during its ascent on 16 February 2004 at 21:00 UTC. Water vapor volume mixing ratio (left) and relative differences (right) computed after Eq. (1). Between 8 and $11 \mathrm{~km}$ altitude the horizontal water vapor variability (yellow box) is estimated to $\pm 20 \%$ from the DIAL data. Larger tropospheric variability below $8 \mathrm{~km}$ altitude and the failure of the TDLAS above $11 \mathrm{~km}$ limit the useful comparison range. Note the excellent overlap between individual subsequent DIAL profiles, confirming the high instrument's accuracy.

ble 1 an absorption cross section accuracy of $2-5 \%$. This represents a constant bias for each line that can be reduced as soon as more accurate line parameters become available. Uncertainties in other line parameters like air and self broadening are comparably small. The more recent HITRAN 2006 release is very similar regarding the lines used here. To evaluate the contribution of individual instrumental and retrievalrelated effects to the overall DIAL accuracy sensitivity analyses were undertaken. A representative UT/LS water vapor profile (from Fig. 3) served as reference. It was close in space and time with the SF1 balloon ascent discussed in Sect. 3.1 that provided water vapor, pressure and temperature profiles. The DIAL radiation transfer code was repeated 
with realistic variations of critical DIAL retrieval input parameters, whereby only one parameter was varied at the same time. The relative differences between the reference and variation runs are displayed in Fig. 1 and vertically averaged listed in Table 2.

The correction of the Rayleigh Doppler effect is the most important accuracy aspect. The backscatter ratio, the ratio of total (aerosol plus molecular) to molecular backscatter coefficients, is the critical input parameter for the Rayleigh Doppler effect correction and can be determined by lidar inversion of the offline backscatter profiles. It amounts to 1.5 in the reference profile composed of background aerosol without clouds, i.e. $33 \%$ aerosol contribution to the total scatter at $940 \mathrm{~nm}$, nearly constant between 8 and $16 \mathrm{~km}$. In a worst case scenario assuming no aerosol at all (backscatter ratio $=$ 1.0) the bias would amount to $3-5 \%$ between 8 and $16 \mathrm{~km}$, increasing with altitude. Approximately the same bias with inverse sign would result if instead of using the true value of 1.5 one would erroneously apply a backscatter ratio of 2.0 for the correction of the Rayleigh Doppler effect. In case of no correction at all, a bias of 5-9\% between 8 and $16 \mathrm{~km}$ would result in the clear-air situation of this analysis (not shown). Note that the Rayleigh Doppler effect may generate larger deviations in the vicinity of aerosol concentration gradients or at the border of clouds, and the correction would require more sophisticated tools (Ansmann and Bösenberg, 1987). Since the study focuses on cloud-free profiles this is not relevant here.

Figure 1 shows that uncertainties in laser spectral purity contribute a bias of $1.0-1.4 \%$. The reference value of $100 \%$ represents pure monochromatic laser radiation. The variation was run with a spectral purity of $99 \%$. This is a realistic assumption since the worst case is $98 \%$, profiles with lower spectral purity being discarded as explained above. The low bias by spectral impurity is due to the fact that the total water vapor optical depth at the online wavelength in the UT/LS is only $\sim 0.3$, even when using the strong absorption line, because of the low water vapor concentrations. Figure 1 has an interruption at $11.5 \mathrm{~km}$ altitude where the measurement switches between the strong and the medium absorption line of Table 1. The strongest jump occurs in the variation run of the spectral purity because this bias is measurement-range dependent. Both absorption lines exhibit very small temperature dependencies. Realistic variations of the air temperature and pressure were estimated from a comparison of tropical radiosonde data at $200 \mathrm{hPa}(\sim 12 \mathrm{~km})$ during the campaign and were found to lie within $\pm 2 \mathrm{~K}$ and $\pm 4 \mathrm{hPa}$. The resulting vertically averaged sensitivities of $0.2 \%$ and $1.4 \%$, respectively, are due to spectroscopic temperature and pressure dependencies and due to the conversion from number density to mixing ratio in which the air density is needed. The temperature sensitivity is small because the effects partially cancel each other.

In addition to systematic uncertainties the DIAL profiles contain statistical uncertainties primarily due to detector and background light noise. This uncorrelated noise can be reduced by appropriate averaging. Since it is to good approximation Gaussian distributed, averaging over $\mathrm{n}$ profiles reduces the noise level by $\sqrt{ } \mathrm{n}$. Therefore the best strategy in homogeneous situations is to average over as many lidar profiles as possible. Zenith-pointing DIAL measurements suffer from a rapidly decreasing SNR with range or height, because molecular scattering, aerosol, and water vapor concentrations decrease roughly exponentially with height. This effect can be compensated by altitude-adapted smoothing. In this study, a linear increase with height of the vertical averaging window size was applied to all water vapor profiles in order to obtain a nearly constant noise level of approximately $3 \%$ on average. Consequently the vertical resolution degrades with height, with typical values of $200 \mathrm{~m}$ in the near-range to $1000 \mathrm{~m}$ in the far range. The water vapor (aerosol) measurements range between 0.2 and $6.5 \mathrm{~km}(10 \mathrm{~km})$ distance above the aircraft which gives top altitudes of $17.5 \mathrm{~km}(21 \mathrm{~km})$ at the typical flight altitude of $11 \mathrm{~km}$. Since the fluctuations of instrument noise, backscatter ratio, spectral purity, pressure and temperature are basically uncorrelated and random, it is possible to add them geometrically. The total DIAL accuracy amounts to $\sim 5 \%$, plus a constant bias of $2-5 \%$ due to the absorption cross section uncertainty (cf. Table 2 ).

\subsection{Measurement strategy and example: outflow of convec- tion into the TTL}

During TROCCINOX a main objective of the DLR Falcon aircraft with the DIAL on board was to profile the TTL water vapor and aerosol/cloud structures in the vicinity of deep convection and in clear sky, in order to learn more about the variability of water vapor in the TTL and the associated UT/LS transport processes. The Falcon was also equipped with in-situ trace gas analyzers to cover the other TROCCINOX objectives. The common strategy was to fly into and around thunderstorms, to serve as a "pathfinder" for the Geophysica aircraft, to do coordinated measurements with that aircraft and with balloons, and to underfly ENVISAT for validation experiments. A particularly interesting case is documented in Fig. 2 where the water vapor anvil outflow of a convective system into the cloud-free TTL could be measured. During this survey and ENVISAT comparison flight on the morning of 3 March 2004 (see also Sect. 3.3), largescale $\mathrm{NO} / \mathrm{NO}_{\mathrm{y}}$ enhancement was measured in the region of predicted lightning $\mathrm{NO}_{\mathrm{x}}$ outflow, and enhanced volatile condensation nuclei were encountered. The lidar backscatter at 532 and $1064 \mathrm{~nm}$ reveals a persistent layer with low depolarization ratio and high color ratio between 12 and $14.5 \mathrm{~km}$ altitude. The depolarization ratio is the ratio of perpendicular to parallel (same polarization plane as the laser) detected signals and allows the discrimination between spherical (no depolarization; e.g. liquid droplets) and non-spherical particles (e.g. ice crystals). The color ratio is the ratio of backscatter coefficients at 532 and $1064 \mathrm{~nm}$. It allows a rough size 
discrimination between particles that are smaller than the wavelength (Rayleigh regime: color ratio $>1$ ) and larger particles where geometrical optics apply (color ratio $\sim 1$ ). Consequently the lidar measurements suggest the presence of small $(<1 \mu \mathrm{m})$ spherical particles which corroborates the in-situ results.

Figure 2 shows a distinct $\sim 200 \mathrm{~m}$ thin humid layer that extends $\sim 40 \mathrm{~km}$ out of the main convective air plume in an altitude of $12.7 \mathrm{~km}$, fully embedded in the layer with the small spherical particles. The particle layer is homogenous, and clouds were not present in the area of Fig. 2. Cirrus clouds with high depolarization and a color ratio of $\sim 1$, i.e. ice crystals larger than $1 \mu \mathrm{m}$, pertaining to the thunderstorm anvil were detected by the lidar at a distance of $\sim 30 \mathrm{~km}$ outside the right (northwest) edge of Fig. 2. They extended vertically between 12 and $14 \mathrm{~km}$ altitude and across $150 \mathrm{~km}$ in the horizontal. From these observations we conclude that the outflow was primarily directed horizontally and that the main convective activity was located about $100 \mathrm{~km}$ away from the outflow region displayed in Fig. 2. The DIAL measurement was made at $23^{\circ} \mathrm{S}$ within tropical air masses, $\sim 200 \mathrm{~km}$ to the northeast of a cold front approaching from southwest. The altitude of the convective outflow fits the expected range (10$14 \mathrm{~km}$ ) of a climatology from Gettelman et al. (2004). Between 12.2 and $13 \mathrm{~km}$ we find an enhancement of the background TTL humidity $(\sim 30 \mu \mathrm{mol} / \mathrm{mol})$ by a factor of two to four across $\sim 100 \mathrm{~km}$. Above the outflow between 13 and $13.7 \mathrm{~km}$ there is still $\sim 50 \%$ more humidity than in the left half of Fig. 2. The flight gave the opportunity to sample another thunderstorm anvil in the same region at similar altitude that did not show an enhancement of water vapor in its outflow region. Many tropical convective cells developed in the region in the afternoon of this day, and the Falcon performed a second flight to probe these with the in-situ instrumentation.

\subsection{Comparison method}

Intercomparisons during field experiments are an important means of quality control. Even if the "true" absolute value remains uncertain due to biases inherent to all instruments taking part in the intercomparison effort, at least an uncertainty range can be derived from the relative differences between the data. Helpful is the fact that the instruments compared here use physically different measurement principles, while DIAL relies on absorption characteristics of a few individual water vapor lines and is basically calibration-free. The zenith-viewing DIAL gave vertical profiles between approximately $200 \mathrm{~m}$ above the aircraft up to a maximum of $18 \mathrm{~km}$ altitude. The maximum range basically depends on the selected absorption line, the abundance of water vapor and the amount of solar background light, whereby night observations are more favorable. Profiles from in-situ instruments are obtained during ascents or descents of the platform they are mounted onto (aircraft or balloon). They are useful as long as the probed air mass is horizontally homogeneous within the profiled volume. In the clear-air TTL stratification dominates and horizontal water vapor gradients are on much larger spatial scales than vertical gradients. This is not the case in the vicinity of convective systems, as we can see in Fig. 2. For the intercomparisons the weather situation and the two-dimensional vertical DIAL cross-sections were analyzed to determine whether horizontal homogeneity was present or not. The water vapor variability between the DIAL and the insitu profiles was estimated from the differences between DIAL profiles over a comparable distance. The fact that in our study no instrument can be considered as an absolute reference has consequences for evaluating the relative differences between the instruments. We follow the neutral approach by Behrendt et al. (2007) and Flentje et al. (2007) and formulate:

$\delta_{\mathrm{H}_{2} \mathrm{O}}(h)=2\left(q_{X}(h)-q_{\text {DIAL }}(h)\right) /\left(q_{X}(h)+q_{\text {DIAL }}(h)\right)$,

whereby $q(h)$ is the water vapor volume mixing ratio (in ppmv or $\mu \mathrm{mol} / \mathrm{mol}$ ) at the height $h . X$ stands for any of the instruments compared with DIAL. The mean of the relative differences $\delta_{\mathrm{H}_{2} \mathrm{O}}$ over all heights gives the average bias between instrument $X$ and the DIAL, and the corresponding standard deviation is a proxy for the accuracy of the comparison. It is a measure of scatter due to poor sampling, instrument noise or natural variability. In the UT, $q$ roughly decreases exponentially with height. Hence relative instead of absolute differences are more appropriate. Note that the exponential q profile induces a wet bias when instruments have poor vertical resolution. However, the DIAL near-range resolution within this critical region is better than $300 \mathrm{~m}$ (see Fig. 2). In the far range where the DIAL resolution becomes worse the measurements are close to the hygropause or within the lower stratosphere where the altitude dependence is no longer exponential. Therefore, the DIAL vertical resolution is not expected to produce a bias.

\section{Intercomparisons with other instruments}

\subsection{Comparisons with a balloon borne laser absorption spectrometer}

In the frame of the HIBISCUS experiment a short-duration flight balloon (SF1) was launched on 16 February 2004 at 20:24 UT in Bauru, Brazil (Pommereau et al., 2007). On board was a near-infrared tunable diode laser absorption spectrometer (TDLAS) from the UK National Physical Laboratory (Gardiner et al., 2005). The instrument uses an astigmatic Herriott cell to measure absorption over a path length of up to $101 \mathrm{~m}$. Different versions of the instrument have been used for balloon-borne (van Aalst et al., 2004) and aircraft-borne (Bradshaw et al., 2002) studies of atmospheric transport and mixing. Water vapor is detected in direct absorption mode by scanning over three main absorption lines 
between 7339.2 and $7341.3 \mathrm{~cm}^{-1}(\sim 1362.4 \mathrm{~nm})$. The lines have different absorption cross sections to cope with the wide dynamic range required in the UT/LS. The data analysis was carried out using the HITRAN 2004 parameters (Rothman et al., 2005). The estimated measurement accuracy is $10 \%$ and the detection limit is $0.5 \mu \mathrm{mol} / \mathrm{mol}$ (Gardiner et al., 2005). The profile shown in Fig. 3 is from the balloon ascent up to $11 \mathrm{~km}$. Unfortunately the instrument failed above that altitude.

The meteorological situation at the site of the balloon ascent $\left(22^{\circ} \mathrm{S}, 49^{\circ} \mathrm{W}\right)$ was characterized by stable tropical air masses at the southern edge of the Bolivian anticyclone. The subtropical jet stream located to the south provided moderate upper level convergence and westerly wind. No upper level clouds or deep convection were observed. To measure background atmospheric parameters in clean air and do comparisons with the balloon the DLR Falcon made a coordinated flight. A descent of the aircraft performed at the same time as the balloon ascent at an average distance of $75 \mathrm{~km}$ gave five consecutive DIAL profiles between 5 and $16 \mathrm{~km}$ altitude using the medium and strong absorption lines of Table 1. Figure 3 shows good agreement $(0.1 \% \pm 19 \%$; computed with Eq. 1) with the TDLAS between 8 and $11 \mathrm{~km}$ where the tropospheric variability was $\sim 20 \%$. The standard deviation of $19 \%$ can mainly be explained by this variability that was estimated from the relative differences between DIAL profiles separated by an equivalent distance. Below $8 \mathrm{~km}$ the tropospheric variability becomes too large for intercomparisons. Note the excellent vertical overlap between all successive DIAL profiles of the Falcon descent, in particular at $11 \mathrm{~km}$ where the switch between the medium and the strong line occurred. This corroborates the high DIAL accuracy since each profile represents an independent measurement. The DIAL vertical resolution goes linearly from $100 \mathrm{~m}$ in $5 \mathrm{~km}$ to $1000 \mathrm{~m}$ in $15 \mathrm{~km}$ altitude. Unfortunately another intercomparison attempt (with the HIBISCUS SF3 balloon) failed because trajectory analyses revealed that strong winds had carried the air mass probed by the balloon too far away in a direction opposite to the Falcon flight path.

\subsection{Comparisons with the Geophysica hygrometers}

A rigorous selection process to find the best intercomparison cases has to consider instrument particularities. For example, in-situ hygrometers may suffer from a wet bias during ascent because of memory effects. Hence for all comparisons with the Geophysica hygrometers, only profiles obtained during descents of the aircraft were used. Unfortunately most of the Geophysica descents were not collocated with DIAL profiles. In addition, opportunities were lost by instrument failures, horizontal water vapor gradients or cirrus clouds. This decreased nine potential intercomparison cases with Geophysica descents to five. The aircraft had three in-situ hygrometers on board for different tasks: while the FLASH instrument had a ventilated inlet that was oriented perpendicularly to the flight direction in order to measure the pure gas phase water, the FISH instrument "looked" into the flight direction and sampled total water using a heated inlet to evaporate liquid and ice particles. In addition, the Aircraft Condensation Hygrometer $(\mathrm{ACH})$, a dew point mirror instrument, was supposed to provide a calibration-free water vapor reference for the Lyman- $\alpha$ hygrometers FLASH and FISH. However, it delivered reliable data in the stratosphere only after a considerable adjustment time ( $\sim 1 \mathrm{~h}$; C. Schiller, personal communication) necessitating a constant flight level. It was not designed to respond to rapid humidity changes and therefore could not be used in the present study which is exclusively exploiting Geophysica descents that were performed within a shorter time frame. Comparisons with DIAL profiles on two such occasions revealed an ACH dry bias of $36 \% \pm 14 \%$ between altitudes of 12 and $16 \mathrm{~km}$, clearly indicative of a too long response time.

The Fluorescent Advanced Stratospheric Hygrometer (FLASH; Sitnikov et al., 2007) applies a method based on the photo-dissociation of the $\mathrm{H}_{2} \mathrm{O}$ molecule when exposed to radiation at a wavelength of $121.6 \mathrm{~nm}$ (the Lyman- $\alpha$ hydrogen emission) provided by a hydrogen discharge lamp. The generated electronically excited $\mathrm{OH}$ radical relaxes to ground state by fluorescence as well as by collision with air molecules. The $\mathrm{OH}$ fluorescence ranges within $308-316 \mathrm{~nm}$, passes a narrowband interference filter, and is detected with a photomultiplier. The intensity of fluorescent light is directly proportional to the water vapor mixing ratio under stratospheric conditions. The instrument has to be calibrated. Long-term stability and calibration tests performed in the laboratory have demonstrated that the accuracy is $<9 \%$ under stratospheric conditions. A recent intercomparison study in the Arctic stratosphere with the balloon version showed agreement within the instrument's accuracy (Vömel et al., 2007). The Fast In-situ Stratospheric Hygrometer (FISH) is based on the same photo-fragment fluorescence technique as FLASH but using a somewhat different design (Zöger et al., 1999). Calibration is performed before each flight with a calibration bench simulating UT/LS mixing ratios and a frost point hygrometer as reference. The overall accuracy is $6 \%$. The forward-facing inlet allows for a sampling of total water, i.e. the sum of gas-phase and condensed $\mathrm{H}_{2} \mathrm{O}$ with an enhanced sampling efficiency for particles. The instrument is used on balloon and aircraft since almost two decades and has been compared to various other in-situ hygrometers and remote-sensing instruments (e.g. Kley et al., 2000).

Figure 4 shows the results of all five Geophysica-DIAL intercomparisons. The apparent heterogeneity reflects the high variability between tropical and mid-latitudes. Table 3 lists all results in detail. The first opportunity for intercomparison was on 18 January 2005 during a test flight in southern Germany where both aircraft followed a $100 \mathrm{~km}$ long "racetrack" pattern at the same time. In order to obtain a nearly noise-free profile up to $18 \mathrm{~km}$ the DIAL profiles were averaged over $36 \min (391 \mathrm{~km})$ along that pattern. The mean 
distance between all averaged DIAL profiles and the Geophysica descent performed along the same track was $32 \mathrm{~km}$, giving the best co-location of the study. Figure 4a shows that pure stratospheric air with low $( \pm 5 \%)$ variability was sampled in the vertical range between 11.6 and $18 \mathrm{~km}$, as expected in a stable mid-latitude winter situation. The variability was estimated from the DIAL data by computing the average relative differences (after Eq. 1) between all individual DIAL profiles separated by $32 \mathrm{~km}$, in order to obtain a proxy for the variability expected at the mean distance to the Geophysica. The profiles of the relative differences FLASHDIAL and FISH-DIAL computed following Eq. (1) oscillate within $\pm 20 \%$ and the vertically averaged differences are within $\pm 6 \%$ (see Table 3 ). This is close to the natural variability and to the accuracy of any of the three instruments and represents an excellent result in very dry air $(3-4 \mu \mathrm{mol} / \mathrm{mol}$ mixing ratio).

The second intercomparison opportunity occurred two days later at the end of the first transfer flight to Brazil shortly before both aircraft landed for a stopover in Spain. Both aircraft were co-located, but since the DIAL did not operate during the Falcon descent, the center of the DIAL profiles averaged over $10 \min (132 \mathrm{~km})$ was $312 \mathrm{~km}$ to the northeast of the Geophysica descent. Horizontal variability is estimated to $\pm 10 \%$ by the DIAL two-dimensional water vapor measurements across that distance. While again most of the discrepancies can be explained by this natural variability and good agreement with FLASH is found, FISH shows higher values below $13 \mathrm{~km}$ and above $15.5 \mathrm{~km}$. The reason is the presence of subvisible cirrus below $13 \mathrm{~km}$ and a distinct background stratospheric aerosol layer above $15.5 \mathrm{~km}$, both visible in the lidar backscatter profiles. Ice particles increased the total water sampled by FISH, whereas FLASH only measured the gas phase. The cirrus is embedded in a layer of high relative humidity close to the cold point tropopause, as observed by the small separation between the mixing ratio and the ice saturation profiles in Fig. 4b. During the campaign in Brazil we unfortunately found only one Geophysica intercomparison opportunity with limited value, because this kind of validation was not a priority of the TROCCINOX experiment. On 15 February 2005 the Geophysica made a "dive" in the eastern part of a local research flight to obtain vertical profiles in a region where thunderstorms had formed the day before. It was $101 \mathrm{~km}$ away from the center of the DIAL profiles averaged over $18 \mathrm{~min}(216 \mathrm{~km})$ and measured at the same time. We find the DIAL values on average $\sim 18 \%$ more humid than the two Geophysica hygrometers and attribute this to moderate heterogeneity of the water vapor field as expected when probing thunderstorms remnants. It is likely that the natural variability of $8 \%$ deduced from the DIAL 2-d cross section is underestimated here because the Falcon did not follow the Geophysica into the region with high variability. The heterogeneity increases considerably below $13.3 \mathrm{~km}$ (DIAL observes more humidity), thus restricting the useful comparison range to $\sim 2 \mathrm{~km}$ in the vertical. The case is nevertheless
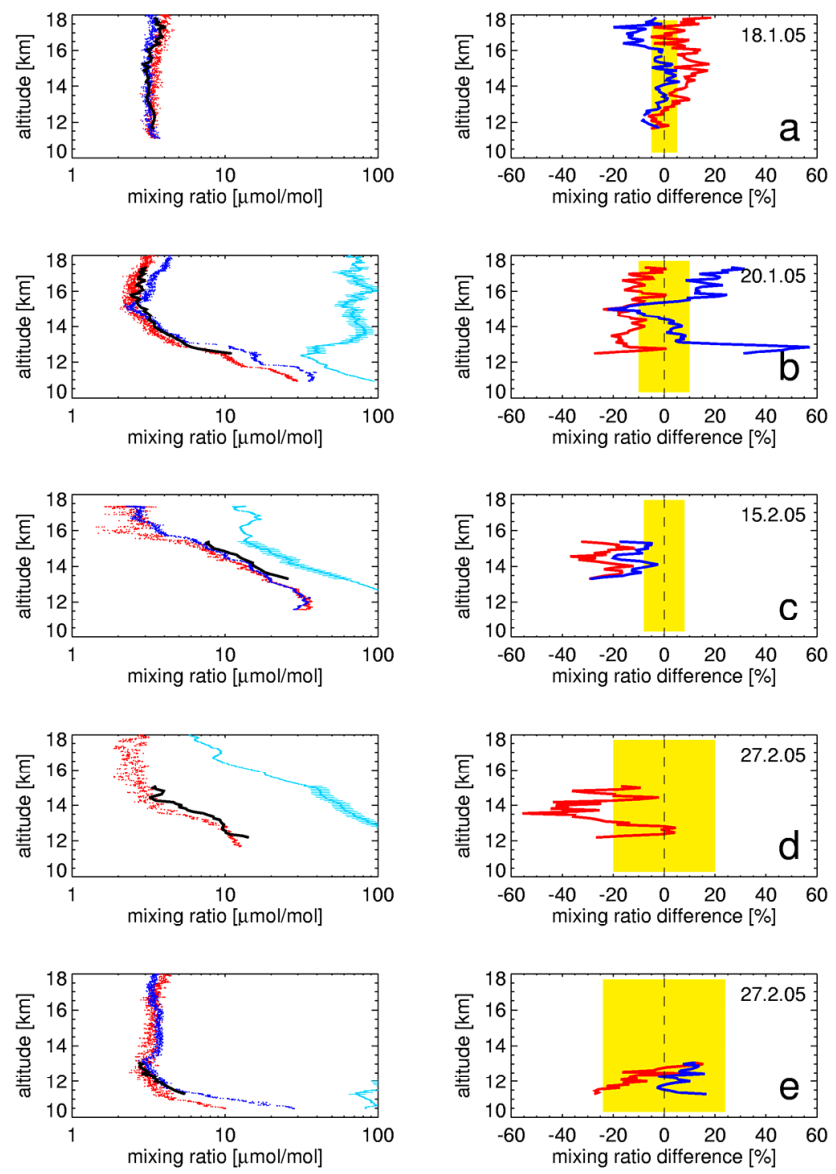

Fig. 4. Comparison between DIAL (black), FISH (blue) and FLASH (red) profiles from Geophysica descents. Left: Water vapor volume mixing ratio and ice saturation from Geophysica temperature measurements with $\pm 1 \mathrm{~K}$ uncertainty range for DIAL profile altitudes (light blue). Right: differences between DIAL and FISH (FLASH) in blue (red) computed after Eq. (1). Yellow boxes: water vapor variability estimated to $\pm 5 \%$ (a), $\pm 10 \%$ (b), $\pm 8 \%$ (c), $\pm 20 \%$ (d) and $\pm 24 \%$ (e) from the DIAL.

interesting since it represents the only Falcon-Geophysica intercomparisons within the TTL.

The last two intercomparison occasions were on the transfer back from Brazil on 27 February 2005 during Geophysica descents before landing. Due to logistical reasons there was no exact coincidence in space and time. The twodimensional DIAL cross sections show horizontal variability of $\pm 20 \%$ and $\pm 24 \%$ over the $\sim 100 \mathrm{~km}$ average distance between the probed air masses. Unfortunately the FISH instrument failed just before the first descent, so that only FLASH could be compared to DIAL in Fig. 4d. We find DIAL more humid by $21 \%$, but large scatter in the differences that can be attributed to natural variability below $14 \mathrm{~km}$ and to instrument noise dominating above. In particular, the FLASH time series oscillates between 2 and $3 \mu \mathrm{mol} / \mathrm{mol}$ before and during the Geophysica descent down to $14 \mathrm{~km}$, 
Table 3. Results of intercomparisons between the water vapor DIAL and vertical profiles from balloon, aircraft and satellite instruments. Relative differences computed after Eq. (1). Positive differences mean DIAL drier.

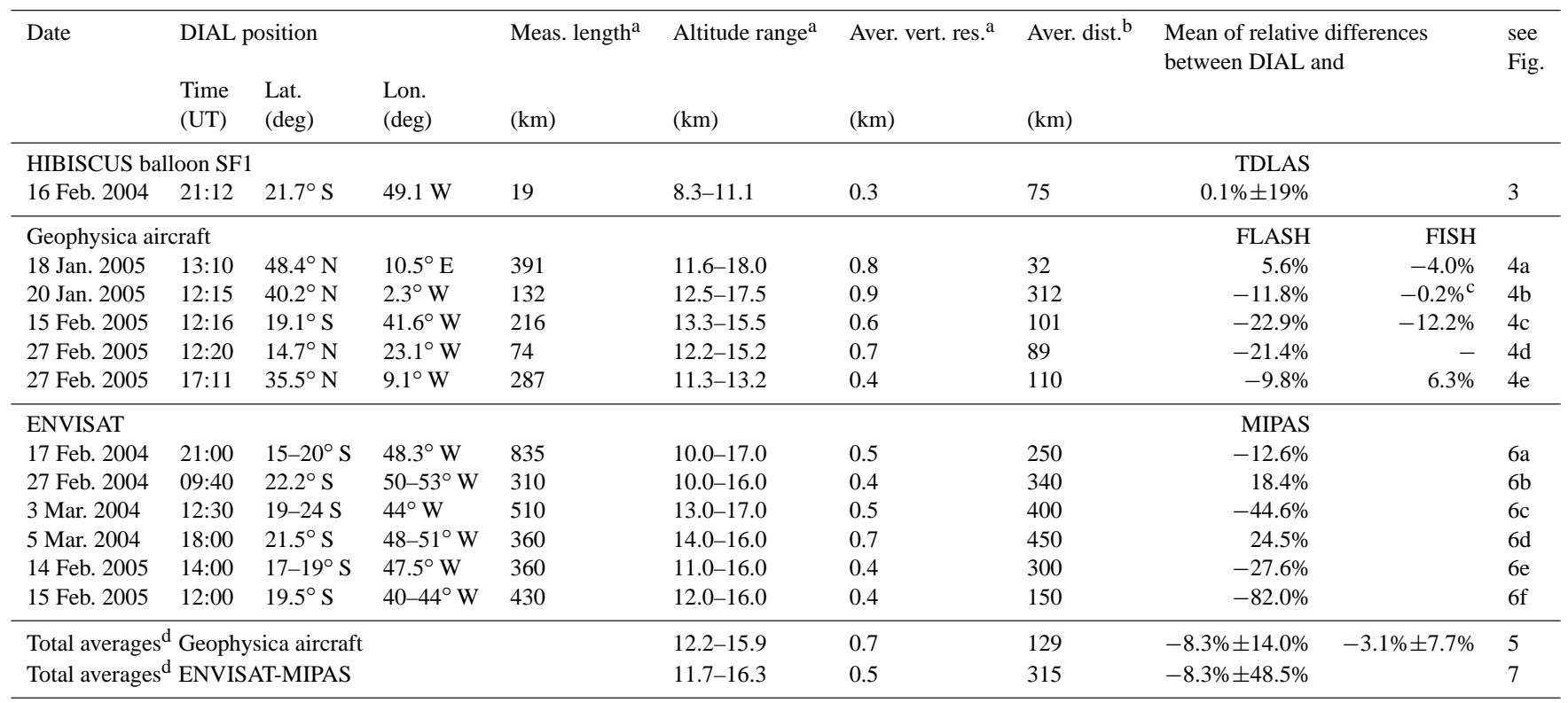

${ }^{a}$ For the DIAL measurements.

b Approximate distance between center points of sampled air masses from trajectory analyses.

c Between 13 and $15.5 \mathrm{~km}$ altitude.

${ }^{\mathrm{d}}$ Averages and standard deviations using all appropriate DIAL profiles. Weighting is proportional to altitude range.

which is perceptible as scatter in the corresponding mixing ratio profile of Fig. 4d. The last intercomparison opportunity is limited by high DIAL instrument noise that lowers the profile top to $13.2 \mathrm{~km}$. We find good agreement within $\pm 10 \%$ on average with FISH and FLASH, well within the natural variability. In conclusion, the first intercomparison (Fig. 4a) is by far the best one due to both the smallest distance between compared profiles $(32 \mathrm{~km})$ and the smallest atmospheric water vapor heterogeneity $(5 \%)$. This coincides with the best agreement found between DIAL, FISH and FLASH $( \pm 6 \%)$. Nevertheless the investigation of subtropical and tropical profiles is useful to verify the behavior of the DIAL in other climates, even if conditions as good as in Fig. 4a were not encountered any more. Figure 5 shows that there is no significant altitude dependent bias in the overall results. When the differences are averaged vertically, best agreement and lowest scatter $(-3 \% \pm 8 \%$; see Table 3 ) is found in the four comparisons with the FISH instrument. Good agreement $(-8 \% \pm 14 \%)$ and moderate scatter is observed for the five comparisons with FLASH. These values are well within the instruments' accuracies. Despite the small number of cases and the overall average distance of $129 \mathrm{~km}$ between the probed air masses we find satisfying agreement at low standard deviation between DIAL, FISH and FLASH over a variety of UT/LS situations ranging from the mid-latitudes to the tropics. This corroborates the results of the DIAL sensitivity study in Sect. 2.2 and the excellent agreement of the best intercomparison opportunity in Fig. 4a.

\subsection{Comparisons with MIPAS onboard ENVISAT}

The Michelson Interferometer for Passive Atmospheric Sounding (MIPAS) is a high-resolution limb-viewing Fourier transform spectrometer onboard ESA's polar sunsynchronous orbiting ENVISAT mission. It observes the Earth's radiance in the mid-infrared region with a spectral range of $4.15-14.6 \mu \mathrm{m}\left(685-2410 \mathrm{~cm}^{-1}\right)$ at a spectral resolution of $0.035 \mathrm{~cm}^{-1}$ and a $3 \times 30 \mathrm{~km}$ field of view. It makes 14 orbits per day and collects radiance spectra that contain information on at least 25 atmospheric constituents including clouds and aerosols, from 68 to $6 \mathrm{~km}$ with a vertical sampling of $3 \mathrm{~km}$ in the lower part (Fischer et al., 2007). MIPAS was operated in its specified high resolution mode until end of March 2004 when an instrument failure forced the interruption of the measurements. MIPAS resumed its operation in a reduced spectral resolution mode in January 2005, now providing radiance profiles with $0.0625 \mathrm{~cm}^{-1}$ spectral resolution at a vertical sampling of $1.5 \mathrm{~km}$ in the UT/LS range, which, in general, leads to a better vertical resolution of the retrieved trace gas profiles. Limb emission spectra are highly influenced by clouds that emit, absorb and scatter radiation over a broad range of wavelengths, resulting in inaccurate 
trace gas concentrations. Therefore, a cloud detection algorithm has been applied to allow identification of cloud-free profiles according to Spang et al. (2004) but using a cloud index of 4 which provides higher sensitivity to thin clouds. Finally, the radiance spectra (level $1 \mathrm{~b}$ data) are used to obtain level 2 vertical profiles for pressure, temperature and numerous trace species including water vapor. For the comparisons presented here we use version V3O_H2O_13 for the 2004 data (MIPAS high spectral resolution mode) and V4O_H2O_202 for the 2005 data (MIPAS reduced spectral resolution mode) produced by the Institut für Meteorologie und Klimaforschung, Karlsruhe, Germany. Only data with the "visibility flag" set were used.

The MIPAS profiles are provided on a 1-km vertical grid and have a vertical resolution of 2 to $4 \mathrm{~km}$. The estimated standard deviation of the individual profiles due to spectral noise is as low as $3-5 \%$ in the tropical UT/LS. However, other random error sources contribute considerably to the total precision (the root mean square of all random errors) which is assessed at $5-10 \%$ in the lowermost stratosphere, $10-25 \%$ in the upper troposphere, and $40-50 \%$ within a narrow altitude range of about $2-3 \mathrm{~km}$ width just below the altitude of the strongest change of vertical gradient of the water vapor mixing ratio profile (below the hygropause). The dominating error source in this region is the pointing uncertainty, assessed at $150 \mathrm{~m}$ (1-sigma), which contributes with $10-20 \%(30-50 \%)$ to the precision in the tropical upper troposphere (hygropause region) and is negligible above. Another relevant error source in the tropical hygropause region is the temperature uncertainty (assessed at $1-2 \mathrm{~K})$. The main systematic error source is spectroscopic uncertainty, contributing with about $10 \%$ to the overall accuracy of $11-14 \% / 42-51 \% / 14-27 \%$ in the lower stratosphere/hygropause region/upper troposphere. The overall accuracy is the root mean square of all random and systematic errors and consequently the relevant number for instrument inter-comparisons. Typical ensemble standard deviations of 5-degree zonal means of global MIPAS observations in the UT/LS, describing both measurement precision and natural variability, are $10-25 \%$, which hints towards a rather conservative error estimation.

Dedicated ENVISAT validation flights were performed with the DLR Falcon during TROCCINOX in 2004 and 2005. Although the aircraft flight path and timing was planned accordingly, logistical and meteorological issues occasionally biased these efforts. A thorough selection of optimum comparison opportunities on the base of meteorological analyses and satellite cloud images left over four cloud-free cases and two cases where cirrus had formed by the time the DIAL performed its measurements. The MIPAS-DIAL comparison was done directly and without convolution of the DIAL profiles with the MIPAS averaging kernels. While the convolution in principle would be necessary since the two measurements have different vertical resolutions, it was not possible to obtain meaningful results in this case due to the

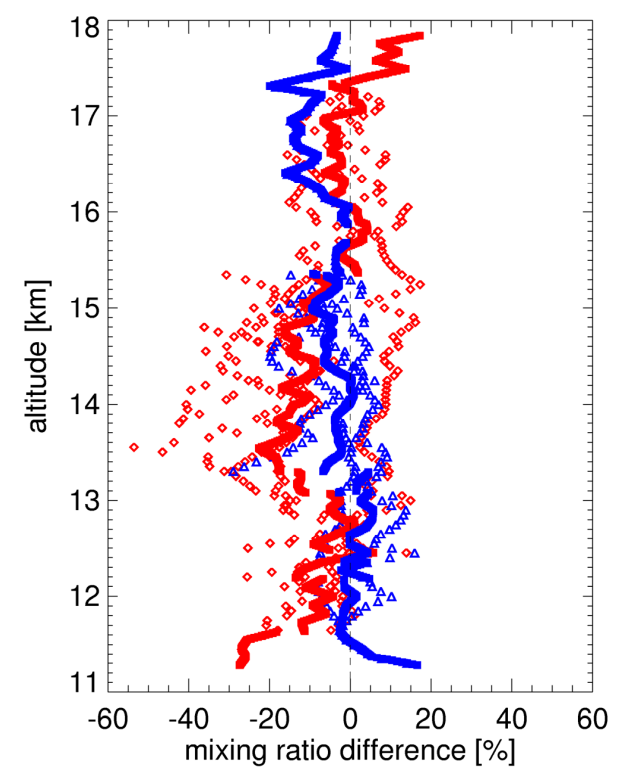

Fig. 5. Overview of all relative differences from Fig. 4 between DIAL and FISH (FLASH) in blue (red); overall averages solid. The average profiles have discontinuities at altitudes where individual profiles stop. Above 15.5 (17.3) km altitude the average difference with FISH (FLASH) is from Fig. 4a only. Positive difference means DIAL drier. There is no significant altitude-dependent bias.

limited altitude coverage of DIAL measurements compared to the width of the MIPAS averaging kernels. With a vertical resolution of 2 to $4 \mathrm{~km}$ (in terms of full width at half maximum of the rows of the averaging kernel matrix), the convolution of the DIAL profiles with the MIPAS averaging kernel was dominated by edge effects coming from altitude ranges where elements of relevant averaging kernel rows were nonzero, but no DIAL measurements were available. Rodgers and Connor (2003) were the first to dig into the problem of comparing profiles with different vertical resolutions. They recommended comparing only total columns, which we find not satisfactory. We prefer to show the profiles as they are and argue that the vertically averaged differences listed in Table 3 are to first order equivalent to the differences between total columns.

Since the spatial and temporal co-location was not as good as with the Geophysica profiles, forward or backward trajectories using the NOAA HYSPLIT online transport model (Draxler and Rolph, 2003) helped to select the closest MIPAS profiles and to estimate the average distance to the DIAL measurements. Cases with distances larger than meso-scales $(500 \mathrm{~km})$ were rejected. This reduced the total number of intercomparison opportunities from originally eleven, to six. Forward trajectories were run when the DIAL flew later than the ENVISAT overpass, backward trajectories in the opposite case. The trajectory start point was set to the place and time of the MIPAS profile under investigation. Trajectories starting at 12,14 and $16 \mathrm{~km}$ altitude and ending at the time 

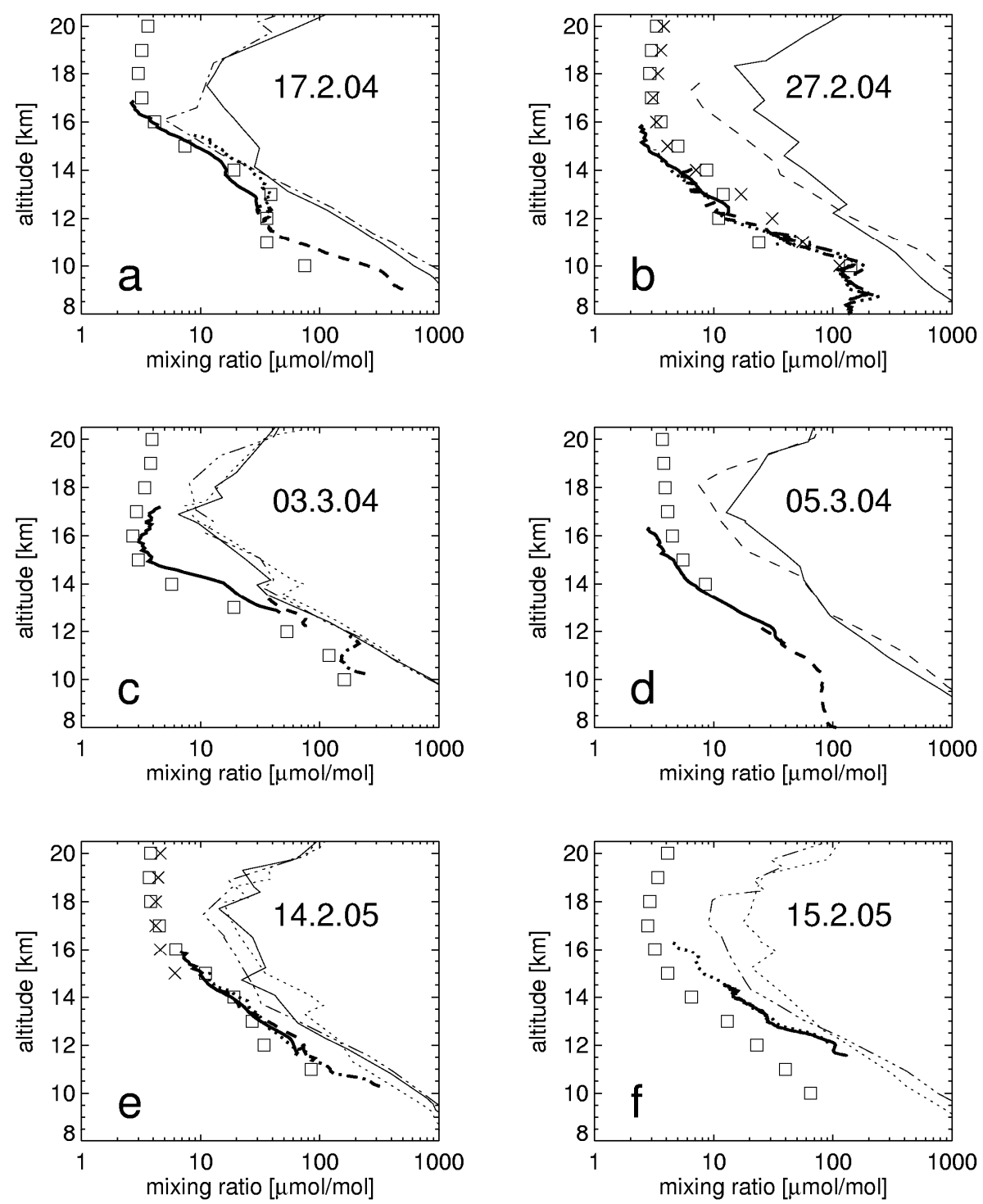

Fig. 6. Comparison between DIAL (thick lines) and ENVISAT/MIPAS (open squares and crosses); (a) and (c) represent cases where anvil cirrus was observed in the vicinity of the non-solid DIAL profiles; the other cases were cloud-free. Thin lines: ice saturation mixing ratio from near-by radiosonde temperature profiles (solid: Marte $23.5^{\circ} \mathrm{S}, 46.6^{\circ} \mathrm{W}$; dotted: Galeao $22.8^{\circ} \mathrm{S}, 43.3^{\circ} \mathrm{W}$; dashed: Campo Grande $20.5^{\circ} \mathrm{S}, 54.7^{\circ} \mathrm{W}$; dash-dotted: Brasilia $15.9^{\circ} \mathrm{S}, 47.9^{\circ} \mathrm{W}$; dash-triple-dotted: Confis $19.6^{\circ} \mathrm{S}, 43.6^{\circ} \mathrm{W}$ ).

of the DIAL measurements were plotted onto a map with the DIAL flight track in order to obtain an overview of the flow situation. This enabled both an altitude-dependent selection of the best coincident DIAL profiles and an assessment of the spatial separation between the probed air masses.

The first good intercomparison opportunity was on 17 February 2004 and is illustrated in Fig. 6a. The Falcon performed a north-south flight parallel to the ENVISAT footprint, at $\sim 150 \mathrm{~km}$ to the east of it and 5-8 $\mathrm{h}$ after the overpass. The meteorological situation in the region was characterized by upper level westerly flow at the southern edge of the Bolivian anticyclone. Air masses affected by tropical convection in the northern part of the flight (dashed and dotted DIAL profiles) contrasted with drier conditions prevailing in the southern part (solid line in Fig. 6a). The contrast also appears in the radiosonde profiles. The flight's scientific objective was to penetrate the convergence zone over the Brazilian highland to the north and to measure cirrus clouds and the flow of nitrogen oxides within this convective region. The westerly flow is observed both in the satellite images and the trajectory analyses and the north-south contrast is well captured by the DIAL. The dotted profile, sampling aged convection outflow, overlaps with the ice saturation profile from the northern radiosonde. This is consistent with the 


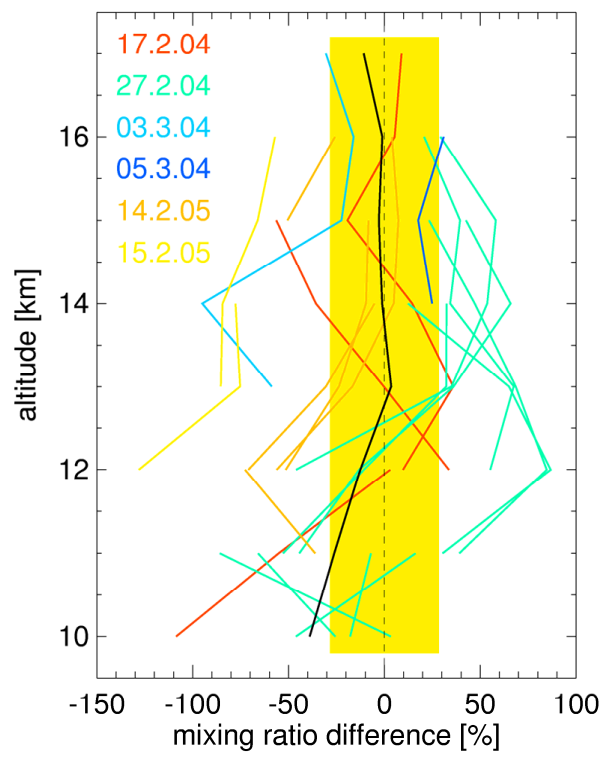

Fig. 7. Overview of relative differences between DIAL and ENVISAT/MIPAS from Fig. 6. The overall mean (black line) and standard deviation is $-8.3 \% \pm 48.5 \%$, above $12 \mathrm{~km}-3.2 \% \pm 48.8 \%$. The water vapor variability (yellow box) is estimated to $\pm 28 \%$ from the DIAL data. Negative difference means DIAL more humid.

lidar observation of widespread anvil cirrus clouds in this region. The MIPAS observation occurred within a cloud-free radius of $\sim 100 \mathrm{~km}$ in the morning (13:27 UT) over the center part of the later Falcon flight. During the 5-8 h that lay between the satellite observation and the flight, the probed air mass moved eastwards. All three DIAL profiles extending in total across $835 \mathrm{~km}$ were used for the comparison. The average air mass distance was $250 \mathrm{~km}$ as estimated from forward trajectory analyses. We find good agreement between MIPAS and DIAL between 10 and $17 \mathrm{~km}$ (within $13 \%$ on vertical average; see Table 3 ).

A more cloud-free and dry situation was encountered on 27 February 2004 where upper level winds from the southwest were present at the southern edge of the Bolivian anticyclone. Both DIAL (9:13-10:05 UT) and MIPAS (13:13 and 13:14 UT) measured in cloud-free conditions. At the end of the flight the Falcon made a stepwise descent that gave the opportunity to probe the middle and upper troposphere down to $4 \mathrm{~km}$ altitude across a length of $310 \mathrm{~km}$. Figure $6 \mathrm{~b}$ shows the MIPAS intercomparison using five DIAL profiles, and Fig. 8 the full composite of eight individual profiles between altitudes of 4 and $16 \mathrm{~km}$, overlapping nearly perfectly. The backward trajectory analyses revealed that two MIPAS profiles (squares and crosses in Fig. 6b) lay within a $500 \mathrm{~km}$ radius of the DIAL probed air mass. Atmospheric homogeneity was high: the solid and dotted DIAL profiles of Fig. $6 \mathrm{~b}$ agree well although being $\sim 250 \mathrm{~km}$ apart. The mean distance between all ten MIPAS-DIAL profile pairs is $340 \mathrm{~km}$. Overall, MIPAS is on average $38 \%$ more humid above $12 \mathrm{~km}$,

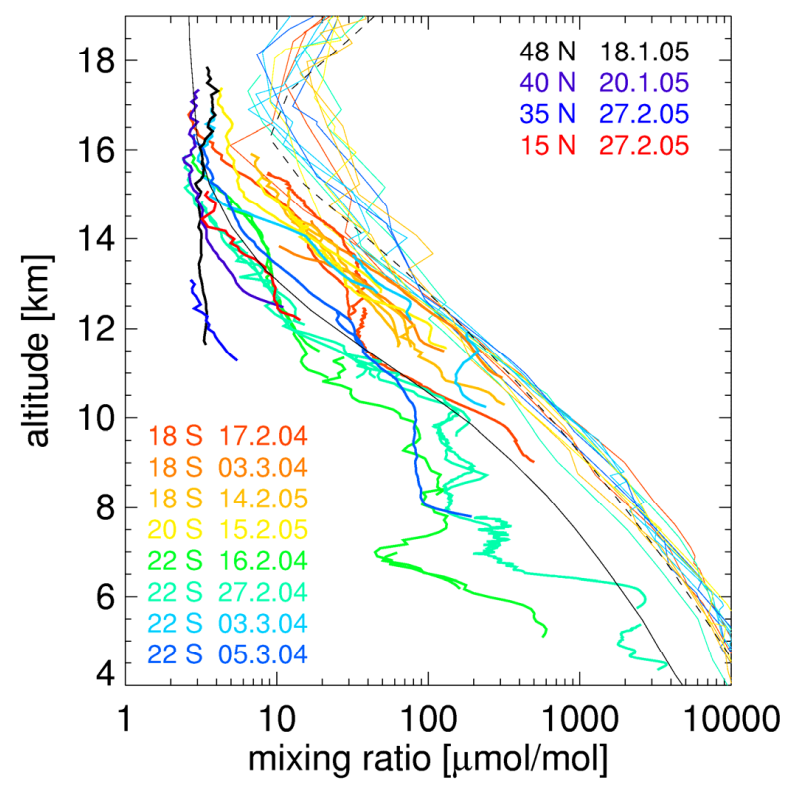

Fig. 8. Overview of all 35 DIAL water vapor profiles used in the study (thick lines). Thin lines: ice saturation mixing ratio from near-by radiosonde temperatures. Tropical standard atmosphere mixing ratio (ice saturation) as thin solid (dashed) black line for comparison. Within 11 and $16 \mathrm{~km}$ a relatively smooth exponential transition from tropospheric to stratospheric humidity is observed. The hygropause with a minimum mixing ratio of $2.5 \mu \mathrm{mol} / \mathrm{mol}$ is roughly located between 15 and $17 \mathrm{~km}$, the cold point tropopause from radiosonde temperatures between 16 and $18 \mathrm{~km}$.

with better agreement below, resulting in a total difference of $\sim 18 \%$.

On the morning of 3 March 2004 the Falcon performed a survey and ENVISAT validation flight in a region subject to tropical convection. In the range of an upper ridge axis of the Bolivian anticyclone, tropical air masses spread into the area ahead of an approaching cold front over Argentina. Instability was sufficient and scattered thunderstorms developed during the day. The MIPAS overpass was at 01:09 UT, about $12 \mathrm{~h}$ earlier than the DIAL measurements already discussed in Sect. 2.3. MIPAS profiled a region ahead of the front, off the Brazilian coast and free of clouds within a radius of $400 \mathrm{~km}$. The forward trajectories show that southerly winds between 12 and $16 \mathrm{~km}$ altitude carried this air mass ahead of the front to a region located $400 \mathrm{~km}$ to the east of the solid DIAL profile of Fig. 6c. The two other DIAL profiles are sampling fresh convection outflow and hence are found approaching the ice saturation profiles from three nearby radiosondes. In particular, the dashed line shows the average profile across Fig. 2. Since these two profiles represent recent convection outflow that occurred after the MIPAS measurement, they are not used for comparison. The natural variability found in the DIAL data across a $400 \mathrm{~km}$ north-south flight leg accounts for $35 \%$ difference. The west-east variability was probably larger due to the $\sim 200 \mathrm{~km}$ distant cold 
front approaching from the southwest, but additional observations to support this hypothesis are lacking. This could be the reason for the relatively large discrepancy where MIPAS is on average $45 \%$ drier than the solid DIAL profile.

Two days later, on 5 March 2004, the DLR Falcon performed a west-east flight at around 18:00 UT in entirely cloud-free conditions with weak westerly flow at upper levels, again at the southern edge of the Bolivian anticyclone. The probed air masses were stable and not affected by convection. The MIPAS profile at 01:47 UT, 16h earlier, was also cloud free. Weak flow above $14 \mathrm{~km}$ altitude led to an average intercomparison distance of $450 \mathrm{~km}$ as estimated by forward trajectory analyses. Figure $6 \mathrm{~d}$ displays two DIAL profiles with excellent overlap at $12 \mathrm{~km}$ altitude, and one MIPAS profile above $14 \mathrm{~km}$. Despite the relatively large temporal and spatial distance, fair agreement (MIPAS 25\% more humid) is found with the upper-level DIAL profile (solid) over a small $(2 \mathrm{~km})$ vertical overlap range.

During the TROCCINOX campaign in 2005, two clearsky intercomparison opportunities with much better temporal overlap than in 2004 were identified. On 14 February, two MIPAS profiles at $\sim 13: 18$ UT were well co-located in time and space with four fully overlapping DIAL profiles between 13:30 and 14:30 UT (Fig. 6e). The latter were measured across $\sim 400 \mathrm{~km}$ during a north-south flight, and the average intercomparison distance was $300 \mathrm{~km}$. We find MIPAS drier below $13 \mathrm{~km}$ and above $15 \mathrm{~km}$, leading to an average difference of $\sim 28 \%$. On the next day the best agreement in time and space was achieved, the DIAL measurements between 11:50 and 12:35 UT being on average $150 \mathrm{~km}$ to the northwest of the MIPAS profile measured at 12:48 UT. Both solid and dotted DIAL profiles were co-located and agree perfectly. Unfortunately, homogeneity across the $150 \mathrm{~km}$ distance between the DIAL and the MIPAS profile locations was worse. This is discussed in Sect. 3.2 where the dotted DIAL profile of Fig. 6f was judged against the Geophysica hygrometers. The comparison of Figs. $4 \mathrm{c}$ and $6 \mathrm{f}$ reveals that the MIPAS profile fits better with the FISH and FLASH instruments. This is not surprising given the fact that the Geophysica descent at 12:20 UT was well co-located with the MIPAS profile. In this part of the flight, a region where thunderstorms had formed the day before, the Falcon unfortunately did not follow the Geophysica. This explains the heterogeneity and the large difference of $-82 \%$ found between the DIAL and MIPAS profiles. This last example highlights the general intercomparison difficulty: despite the best co-location with MIPAS, water vapor variability, difficult to quantify, led to the largest deviations of the study. The recommendation that can also be drawn from the Geophysica comparisons is to imperatively organize future intercomparisons in more homogeneous situations with better co-location.

Figure 7 gives an overview of the inter-comparisons with MIPAS by displaying all relative differences between the individual profile pairs. The scatter can be attributed to instru- ment precision (assessed above), atmospheric temporal and spatial heterogeneity, and to the relatively large average distances between the probed air masses, mainly due to the large time difference between the measurements (6h on average, making a considerable difference regarding the diurnal variation of high-reaching convection). Table 3 shows that the average spatial distances are about 2.5 times larger than for the comparisons with the Geophysica hygrometers, while the temporal distances are about 10 times larger $(6 \mathrm{~h}$ versus $0.6 \mathrm{~h}$ on average), as a consequence of fixed overpass times for the satellite instrument versus optimized Falcon and Geophysica flight planning. The DIAL two-dimensional measurements allow estimating the water vapor spatial heterogeneity at the scale of the distance between the DIAL and MIPAS profiles. They amount, vertically averaged, to $25 \%$ for Fig. 6a, 30\% for Fig. 6b, 35\% for Fig. 6c, 26\% for Fig. 6d, 27\% for Fig. 6e, and $25 \%$ for Fig. 6 . The overall natural variability is $28 \%$ and displayed in Fig. 7. This assessment certainly has its limits as it does not capture the cross-track variability, but there are no better data available. As a consequence of the imperfect co-incidences, the standard deviation of all DIAL differences with MIPAS amounts to $\pm 48.5 \%$ (Table 3 ). This is 4.5 times larger than with the Geophysica hygrometers.

Another aspect to consider within the inter-comparison of a high-spatially resolving lidar instrument, in situ measurements and a space-borne remote-sensing instrument is the sampled air volume: while in-situ instruments provide spot samples of very small air volumes, and lidar instruments of air volumes of some extent in the vertical, but very limited extent in horizontal direction, MIPAS averages over an air volume of about $250 \mathrm{~km}$ times $30 \mathrm{~km}$ in the horizontal and 2 to $4 \mathrm{~km}$ in the vertical direction. Thus, small-scale horizontal heterogeneity sampled by in-situ instruments and DIAL is smoothed out for the MIPAS remote sensing observations, which somewhat hinders a direct inter-comparison based on individual profiles. The mean deviation or bias between MIPAS and DIAL is $-8.3 \%$ ( $-3.2 \%$ above $12 \mathrm{~km}$ altitude). In order to test the significance of this bias, the standard deviation of the mean is the appropriate measure. It is equal to the standard deviation divided by the square root of the number of profiles, altitude dependent, and amounts to 10-20\% with an overall mean of $15 \%$ for the profiles of Fig. 7 . A significant bias is consequently only apparent below $12 \mathrm{~km}$. Despite the large scatter as expressed in the standard deviation, the good average agreement of these comparisons indicates that MIPAS is capable of measuring well the water vapor mixing ratio in the tropical UT/LS, at least in terms of mean distributions, in particular above $12 \mathrm{~km}$ altitude.

\section{Discussion of the DIAL profiles}

The intercomparisons of the previous section, particularly the case of Fig. 4a in which the comparison conditions and the resulting agreement are excellent, give confidence into 
the DIAL results and corroborate the findings of the DIAL sensitivity study in Sect. 2.2. The measurements are obviously very valuable to characterize the water vapor distribution both in the vicinity of deep convection and in clear sky, in order to gain more insight into the variability of water vapor in the TTL and the associated UT/LS transport processes. The vertical cross section of convective outflow in Fig. 2 is an outstanding example of the capability of airborne DIAL to sample interesting, complex situations with high accuracy and spatial resolution.

Figure 8 gives an overview of all 35 DIAL profiles used in this paper. The profiles, obtained using the weak, medium and strong absorption lines of Table 1, cover an altitude region from 4 to $18 \mathrm{~km}$ and water vapor mixing ratios from 2.5 to $4000 \mu \mathrm{mol} / \mathrm{mol}$, i.e. spanning more that three orders of magnitude. While the extra-tropical northern-hemispheric profiles $\left(35-48^{\circ} \mathrm{N}\right)$ between 11 and $15 \mathrm{~km}$ clearly cluster on the dry side, the tropical profiles scatter across a large range up to the ice saturation values in cases where the DIAL measured in between cirrus clouds and in convective outflow, particularly on 3 March 2004. The largest humidity scatter is observed between 11 and $15 \mathrm{~km}$ altitude where the mixing ratios are seen to vary by a factor of 10-20, not counting the extra-tropical profiles. This represents obviously the level of main convective outflow observed during the flights, leading to large variability as seen in Fig. 2. The altitude range fits well the climatology $(10-14 \mathrm{~km})$ by Gettelman et al. (2004) and represents the lower TTL bound. Above $14 \mathrm{~km}$ altitude the scatter between profiles decreases significantly. Below $10 \mathrm{~km}$, tropospheric air is clearly characterized by high humidity and variability.

Above $16 \mathrm{~km}$ altitude the five DIAL profiles covering latitudes between $22^{\circ} \mathrm{S}$ and $48^{\circ} \mathrm{N}$ have clearly stratospheric character: they are nearly vertically constant and range between $3-6 \mu \mathrm{mol} / \mathrm{mol}$. The profile in $48^{\circ} \mathrm{N}$ exhibits intermediate stratospheric values of $\sim 4 \mu \mathrm{mol} / \mathrm{mol}$. In Fig. 8 , all radiosonde profiles and all DIAL profiles between 18 and $22^{\circ} \mathrm{S}$ are within tropical air masses. The driest air (minimum $2.5 \mu \mathrm{mol} / \mathrm{mol}$ ) is found between altitudes of 15 and $17 \mathrm{~km}$. This hygropause altitude is on average $\sim 1 \mathrm{~km}$ lower than the cold point tropopause located between 16 and $18 \mathrm{~km}$, and identified by the altitude of the minimum ice saturation mixing ratio derived from the radiosonde temperature profiles. Since the figure shows a limited sample of profiles with obvious scatter, such general statements have of course to be taken cautiously. Notice finally that between 11 and $16 \mathrm{~km}$ most profiles are quasi straight lines. Instead of a distinct air mass boundary, as is the extra-tropical tropopause, we observe here a smooth, exponentially-shaped transition of the water vapor mixing ratio from tropospheric to stratospheric values in response to the temperature decrease and according to the Clausius-Clapeyron equation.

\section{Conclusions}

The first airborne water vapor differential absorption lidar measurements in the tropical upper troposphere and the midlatitudes lower stratosphere are characterized by high accuracy $(\sim 5 \%)$ and spatial resolution $(2 \mathrm{~km}$ horizontal, 0.2 to $1 \mathrm{~km}$ vertical resolution). Intercomparisons with Lymanalpha in-situ hygrometers at exact co-location show excellent agreement $(<6 \%$ relative differences on average) in the mid-latitudes' lower stratosphere between 11.6 and $18.0 \mathrm{~km}$ altitude, well within the instruments' accuracies. An extension of the intercomparisons to five cases in the subtropics and the tropics gives an overall good agreement $(<9 \%)$ between 8.3 and $17.5 \mathrm{~km}$ altitude, even if these are not exactly co-located and subject to atmospheric water vapor fluctuations. The DIAL has no significant altitude- or latitudedependent bias. Comparisons with the MIPAS instrument on ENVISAT give good agreement (MIPAS on average 8\% drier than DIAL) at however lower statistical significance due to poorer comparison conditions, especially larger distances between the probed air masses. Research flights of the DLR Falcon and the Russian M-55 Geophysica during the TROCCINOX campaigns in 2004 and 2005, and the corresponding coordinated transfer flights between Germany and Brazil provided the data base for this study. The results demonstrate the potential of DIAL to provide accurate water vapor profiles in the UT/LS region. The purpose is to gain more insight into the TTL processes responsible for the transport of water vapor into the stratosphere.

The two-dimensional atmospheric cross sections of water vapor mixing ratio complement and significantly go beyond one-dimensional in-situ observations on balloons or aircraft. This is impressively shown by a DIAL measurement example in which the anvil outflow of a convective system was observed with high spatial resolution. It augmented the ambient TTL humidity by a factor of two to four. The overview of all 35 DIAL profiles between $48^{\circ} \mathrm{N}$ and $22^{\circ} \mathrm{S}$ used in the present study reveals large scatter by reason of the measurement strategy that consisted in probing either the clear-air background or convective outflow events. Most profiles have a smooth exponential transition from tropospheric to stratospheric humidity in response to the temperature decrease. The tropical hygropause with a minimum mixing ratio of $\sim 2.5 \mu \mathrm{mol} / \mathrm{mol}$ is found between 15 and $17 \mathrm{~km}$ altitude, i.e. on average $\sim 1 \mathrm{~km}$ lower than the local cold point tropopause observed by radiosondes. Future work will be dedicated to the exploitation of additional water vapor profiles gained during the SCOUT-O3 campaign in 2005 in Darwin, Australia. About $90 \%$ cloud cover by optically thin cirrus was encountered there. This will require a particular investigation on the accuracy of the DIAL measurements within cirrus. 
Acknowledgements. This work has been partially funded by the European Commission within TROCCINOX (contract EVK2-CT2001-00122) and the European Cooperation in the field of Scientific and Technical Research (COST ES0604). Without the support by the Brazilian Instituto de Pesquisas Meteorologicas (IPMET) of the Universidade Estadual Paulista (UNESP) the measurements would not have been possible. The authors gratefully acknowledge the DLR flight facility and the NOAA Air Resources Laboratory for the provision of the HYSPLIT transport model used in this publication.

\section{Edited by: S. Buehler}

\section{References}

Ansmann, A. and Bösenberg, J.: Correction scheme for spectral broadening by Rayleigh scattering in differential absorption lidar measurements of water vapor in the troposphere, Appl. Opt., 26, 3026-3032, 1987.

Behrendt, A., Wulfmeyer, V., Di Girolamo, P., Kiemle, C., Bauer, H.-S., Schaberl, T., Summa, D., Whiteman, D. N., Demoz, B. B., Browell, E. V., Ismail, S., Ferrare, R., Kooi, S., Ehret, G., and Wang, J.: Intercomparison of Water Vapor Data Measured with Lidar during IHOP_2002, Part I: Airborne to Ground-Based Lidar Systems and Comparisons with Chilled-Mirror Hygrometer Radiosondes, J. Atmos. Ocean. Technol., 24, 3-21, 2007.

Bradshaw, N. G., Vaughan, G., Busen, R., Garcelon, S., Jones, R. L., Gardiner, T., and Hacker, J.: Tracer filamentation generated by small scale Rossby wave breaking in the lower stratosphere, J. Geophys. Res., 107(D23), 4689, doi:10.1029/2002JD002086, 2002.

Chaboureau, J. B., Cammas, J. B., Duron, J., Mascart, P. J., Sitnikov, N. M., and Voessing, H. J.: A numerical study of tropical cross-tropopause transport by convective overshoots, Atmos. Chem. Phys., 7, 1731-1740, 2007, http://www.atmos-chem-phys.net/7/1731/2007/.

Corti, T., Luo, B. P., Peter, T., Vömel, H., and Fu, Q.: Mean radiative energy balance and vertical mass fluxes in the equatorial upper troposphere and lower stratosphere, Geophys. Res. Lett., 32, L06802, doi:10.1029/2004GL021889, 2005.

Draxler, R. R. and Rolph, G. D.: HYSPLIT (Hybrid Single-Particle Lagrangian Integrated Trajectory) Model access via NOAA ARL READY Website (http://www.arl.noaa.gov/ready/hysplit4.html), NOAA Air Resources Lab, Silver Spring, MD, 2003.

Ehret, G., Hoinka, K. P. , Stein, J., Fix, A., Kiemle, C., and Poberaj, G.: Low stratospheric water vapor measured by an airborne DIAL, J. Geophys. Res., 104, 31 351-31 359, 1999.

Fischer, H., Birk, M., Blom, C., Carli, B., Carlotti, M., von Clarmann, T., Delbouille, L., Dudhia, A., Ehhalt, D., Endemann, M., Flaud, J. M., Gessner, R., Kleinert, A., Koopmann, R., Langen, J., López-Puertas, M., Mosner, P., Nett, H., Oelhaf, H., Perron, G., Remedios, J., Ridolfi, M., Stiller, G., and Zander, R.: MIPAS: an instrument for atmospheric and climate research, Atmos. Chem. Phys., 8, 2151-2188, 2008,

http://www.atmos-chem-phys.net/8/2151/2008/.

Flentje, H. and Kiemle, C.: Erosion and mixing of filaments in the arctic lower stratosphere revealed by airborne lidar measurements, J. Geophys. Res., 108, 4232, doi:10.1029/2002JD002168, 2003.
Flentje, H., Dörnbrack, A., Fix, A., Ehret, G., and Holm, E.: Evaluation of ECMWF water vapour fields by airborne differential absorption lidar measurements: a case study between Brazil and Europe, Atmos. Chem. Phys., 7, 5033-5042, 2007, http://www.atmos-chem-phys.net/7/5033/2007/.

Forster, P., Ramaswamy, V., Artaxo, P., Berntsen, T., Betts, R., Fahey, D. W., Haywood, J., Lean, J., Lowe, D. C., Myhre, G., Nganga, J., Prinn, R., Raga, G., Schulz, M., and Van Dorland, R.: Changes in Atmospheric Constituents and in Radiative Forcing, in: Climate Change 2007: The Physical Science Basis. Contribution of Working Group I to the Fourth Assessment Report of the Intergovernmental Panel on Climate Change, edited by: Solomon, S., Qin, D., Manning, M., Chen, Z., Marquis, M., Averyt, K. B., Tignor, M., and Miller, H. L., Cambridge University Press, Cambridge, UK and New York, NY, USA, 2007.

Fueglistaler, S., Wernli, H., and Peter, T.: Tropical troposphereto-stratosphere transport inferred from trajectory calculations, J. Geophys. Res., 109, D03108, doi:10.1029/2003JD004069, 2004.

Gardiner, T., Swann, N., Leggett, G., Woolley, A., Goody, B., and Woods, P.: Trace Water Vapour Measurements and Calibration, Proc. of the Water Vapour in the Upper Troposphere and Lower Stratosphere Workshop, Lancaster University, UK, July 2005.

Gettelman, A., de F. Forster, P. M., Fujiwara, M., Fu, Q., Vömel, H., Gohar, L. K., Johanson, C., and Ammerman, M.: Radiation balance of the tropical tropopause layer, J. Geophys. Res., 109, D07103, doi:10.1029/2003JD004190, 2004.

Held, I. M. and Soden, B. J.: Water vapor feedback and global warming, Annu. Rev. Energy Environ., 25, 441-475, 2000.

Kärcher, B.: Cirrus clouds in the tropical tropopause layer: Role of heterogeneous ice nuclei, Geophys. Res. Lett., 31, L12101, doi:10.1029/2004GL019774, 2004.

Keil, C., Röpnack, A., Craig, G. C., and Schumann, U.: Sensitivity of quantitative precipitation forecast to height dependent changes in humidity, Geophys. Res. Lett., 35, L09812, doi:10.1029/2008GL033657, 2008.

Kley, D., Smit, H. G. J., Vömel, H., Grassl, H., Ramanathan, V., Crutzen, P. J., Williams, S., Meywerk, J., and Oltmans, S. J.: Tropospheric water-vapour and ozone cross-sections in a zonal plane over the central equatorial Pacific Ocean, Q. J. R. Meteorol. Soc., 123, 2009-2040, 1997.

Kley, D., Russell III, J., Phillips, C. (Eds.), Gettelman, A., Harries, J., Mote, P., Oltmans, S., Remsberg, E., Rosenlof, K., and Schiller, C.: SPARC Assessment of Water Vapour in the Stratosphere and Upper Troposphere, WCRP-113, WMO/TD No. 1043, SPARC Report No. 2, 2000.

Konopka, P., Günther, G., Müller, R., dos Santos, F. H. S., Schiller, C., Ravegnani, F., Ulanovsky, A., Schlager, H., Volk, C. M., Viciani, S., Pan, L. L., McKenna, D. S., and Riese, M.: Contribution of mixing to upward transport across the tropical tropopause layer, Atmos. Chem. Phys., 7, 3285-3308, 2007, http://www.atmos-chem-phys.net/7/3285/2007/.

Liu, C. and Zipser, E. J.: Global distribution of convection penetrating the tropical tropopause, J. Geophys. Res., 110, D23104, doi:10.1029/2005JD006063, 2005.

Luo, B. P., Peter, T., Wernli, H., Fueglistaler, S., Wirth, M., Kiemle, C., Flentje, H., et al.: Ultrathin Tropical Tropopause Clouds (UTTCs): II. Stabilization Mechanisms, Atmos. Chem. Phys., 3, 1093-1100, 2003, http://www.atmos-chem-phys.net/3/1093/2003/. 
Müller, S. C., Kämpfer, N., Feist, D. G., Haefele, A., Milz, M., Sitnikov, N., Schiller, C., Kiemle, C., and Urban, J.: Validation of stratospheric water vapour measurements from the airborne microwave radiometer AMSOS, Atmos. Chem. Phys. Discuss., 8, 1635-1671, 2008,

http://www.atmos-chem-phys-discuss.net/8/1635/2008/.

Peter, T., Luo, B. P., Wernli, H., Wirth, M., Kiemle, C., Flentje, H., et al.: Ultrathin Tropical Tropopause Clouds (UTTCs): I. Cloud Morphology and Occurrence, Atmos. Chem. Phys., 3, 1083-1091, 2003,

http://www.atmos-chem-phys.net/3/1083/2003/.

Peter, T., Marcolli, C., Spichtinger, P., Corti, T., Baker, M. B., and Koop, T.: When Dry Air Is Too Humid, Science, 314, 13991402, 2006.

Poberaj, G., Fix, A., Assion, A., Wirth, M., Kiemle, C., and Ehret, G.: Airborne All-Solid-State DIAL for Water Vapour Measurements in the Tropopause Region: System Description and Assessment of Accuracy, Appl. Phys. B, 75, 165-172, doi:10.1007/s00340-002-0965-x, 2002.

Pommereau, J.-P., Garnier, A., Held, G., Gomes, A.-M., Goutail, F., Durry, G., Borchi, F., Hauchecorne, A., Montoux, N., Cocquerez, P., Letrenne, G., Vial, F., Hertzog, A., Legras, B., Pisso, I., Pyle, J. A., Harris, N. R. P., Jones, R. L., Robinson, A., Hansford, G., Eden, L., Gardiner, T., Swann, N., Knudsen, B., Larsen, N., Nielsen, J., Christensen, T., Cairo, F., Pirre, M., Marecal, V., Huret, N., Riviere, E., Coe, H., Grosvenor, D., Edvarsen, K., Di Donfrancesco, G., Ricaud, P., Berthelier, J.-J., Godefroy, M., Seran, E., Longo, K., and Freitas, S.: An overview of the HIBISCUS campaign, Atmos. Chem. Phys. Discuss., 7, 2389-2475, 2007 ,

http://www.atmos-chem-phys-discuss.net/7/2389/2007/.

Rodgers, C. D. and Connor, B. J.: Intercomparison of remote sounding instruments, J. Geophys. Res., 108, D3, 4116, doi:10.1029/2002JD002299, 2003.

Rothman, L. S., Jacquemart, D., Barbe, A., Benner, D. C., Birk, M., Brown, L. R., Carleer, M. R., Chackerian, C., Chance, K., Coudert, L. H., Dana, V., Devi, V. M., Flaud, J.-M., Gamache, R. R., Goldman, A., Hartmann, J.-M., Jucks, K. W., Maki, A. G., Mandin, J.-Y., Massie, S. T., Orphal, J., Perrin, A., Rinsland, C. P., Smith, M. A. H., Tennyson, J., Tolchenov, R. N., Toth, R. A., Vander Auwera, J., Varanasi, P., and Wagner, G.: The HITRAN 2004 molecular spectroscopic database, J. Quant. Spectr. \& Rad. Trans., 96, 139-204, 2005.

Schumann, U. and Huntrieser, H.: The global lightning-induced nitrogen oxides source, Atmos. Chem. Phys., 7, 3823-3907, 2007, http://www.atmos-chem-phys.net/7/3823/2007/.
Sitnikov, N. M., Yushkov, V, A., Afchine, A. A., Korshunov, L. I., Astakhov, V. I., Ulanovskii, A. E., Kraemer, M., Mangold, A., Schiller, C., and Ravegnani, F.: The FLASH instrument for water vapor measurements on board the high-altitude airplane, Russian Journal on Instruments and Experimental Techniques, 50,1, 113121, 2007.

Spang, R., Remedios, J. J., and Barkley, M. P.: Colour indices for the detection and differentiation of cloud types in infrared limb emission spectra, Adv. Space Res., 3, 1041-1047, doi:10.1016/S0273-1177(03)00585-4, 2004.

Stenke, A. and Grewe, V.: Simulation of stratospheric water vapor trends: impact on stratospheric ozone chemistry, Atmos. Chem. Phys., 5, 1257-1272, 2005, http://www.atmos-chem-phys.net/5/1257/2005/.

Thomas, A., Borrmann, S., Kiemle, C., Cairo, F., Volk, M., Beuermann, J., Lepuchov, B., Santacesaria, V., Matthey, R., Rudakov, V., Yushkov, V., MacKenzie, R., and Stefanutti, L.: In situ measurements of background aerosol and subvisible cirrus in the tropical tropopause region, J. Geophys. Res., 107, D24, 4763, doi:10.1029/2001JD001385, 2002.

Trenberth, K. E., Jones, P. D., Ambenje, P., Bojariu, R., Easterling, D., Klein Tank, A., Parker, D., Rahimzadeh, F., Renwick, J. A., Rusticucci, M., Soden, B., and Zhai, P.: Observations: Surface and Atmospheric Climate Change, in: Climate Change 2007: The Physical Science Basis, Contribution of Working Group I to the Fourth Assessment Report of the Intergovernmental Panel on Climate Change, edited by: Solomon, S., Qin, D., Manning, M., Chen, Z., Marquis, M., Averyt, K. B., Tignor, M., and Miller, H. L., Cambridge University Press, Cambridge, UK and New York, NY, USA, 2007.

van Aalst, M. K., van den Broek, M. M. P., Bregman, A., Bruhl, C., Steil, B., Toon, G. C., Garcelon, S., Hansford, G. M., Jones, R. L., Gardiner, T. D., Roelofs, G. J., Lelieveld, J., and Crutzen, P. J.: Trace gas transport in the 1999/2000 Arctic winter: comparison of nudged GCM runs with observations, Atmos. Chem. Phys., 4, 81-93, 2004, http://www.atmos-chem-phys.net/4/81/2004/.

Vömel, H., Yushkov, V., Khaykin, S., Korshunov, L., Kyrö, E., and Kivi, R.: Intercomparisons of Stratospheric Water Vapor Sensors: FLASH-B and NOAA/CMDL Frost-Point Hygrometer, J. Atmos. Ocean. Technol., 24, 941-952, 2007.

Zöger, M., Afchine, A., Eicke, N., Gerhards, M.-T., Klein, E., McKenna, D. S., Mörschel, U., Schmidt, U., Tan, V., Tuitjer, F., Woyke, T., and Schiller, C.: Fast in situ stratospheric hygrometers: A new family of balloonborne and airborne Lyman-alpha photofragment fluorescence hygrometers, J. Geophys. Res., 104, 1807-1816, 1999. 